\title{
Les industries lithiques de trois locus du Mésolithique final à Coulmer (Orne)
}

Die Steingeräteindustrie von drei Fundansammlungen des Endmesolithikums bei Coulmer (Orne)

Industrias líticas de tres locus del Mesolítico final en Coulmer (Orne)

Lithic industries from three Late Mesolithic loci at Coulmer (Orne)

\section{Emmanuel Ghesquière}

\section{(2) OpenEdition}

\section{Journals}

Édition électronique

URL : https://journals.openedition.org/rao/2869

DOI : $10.4000 /$ rao.2869

ISBN : 978-2-7535-5014-8

ISSN : 1775-3732

\section{Éditeur}

Presses universitaires de Rennes

\section{Édition imprimée}

Date de publication : 31 décembre 2015

Pagination : 25-49

ISBN : 978-2-7535-5012-4

ISSN : 0767-709X

\section{Référence électronique}

Emmanuel Ghesquière, «Les industries lithiques de trois locus du Mésolithique final à Coulmer (Orne) », Revue archéologique de l'Ouest [En ligne], 32 | 2015, mis en ligne le 28 avril 2018, consulté le 22 août 2022. URL : http://journals.openedition.org/rao/2869 ; DOI : https://doi.org/10.4000/rao.2869 


\title{
Les industries lithiques de trois locus du Mésolithique final à Coulmer (Orne)
}

\author{
Lithic industries from three Late Mesolithic loci at Coulmer (Orne)
}

\author{
Emmanuel GHesQuière
}

\begin{abstract}
Résumé : Une fouille réalisée en 2010 sur un petit tracé routier près de Gacé (Orne) a livré trois locus partiellement conservés, rattachés au Mésolithique final. Les observations taphonomiques de ces séries incluses dans les limons témoignent probablement pour les locus 1 et 2 de pièces entrainées en profondeur par les agents naturels (terriers, racines...) tandis que la dispersion verticale du mobilier du locus 3 suggère une formation de la concentration par un phénomène de colluvionnement et de piégeage sur le faible relief de la bordure du plateau. De fait, quelques éléments perturbateurs se sont mélangés aux séries mésolithiques (quelques éléments modernes, deux pointes de flèche, un bracelet de schiste, un fragment de hache polie...) mais ne semblent concerner que des éléments isolés, non significatifs et perdus hors de tout contexte d'occupation. Ils témoignent toutefois que l'homogénéité des séries n'est pas totalement acquise. Les artefacts lithiques, taillés à partir de silex ou de grès de qualités médiocres, présentent une série homogène que vient perturber très modestement quelques artefacts du Néolithique ancien et final. Du fait des matières premières utilisées, la production mésolithique s'oriente vers un débitage où la composante lamino-lamellaire est limitée, témoin d'une faible utilisation comme supports d'outils (armatures sur éclat mince, outillage de fonds commun dominé par les éclats retouchés et les grattoirs) et où la production à partir de « micro-nucléus » est fréquente. Le groupe des armatures est représenté par des pointes à troncature gibbeuse, des pointes triangulaires et des pointes segmentiformes épaisses. Le tout semble se rattacher au complexe à armatures à troncature gibbeuse (pointes de Sonchamp, pointes de Falaise...). Malgré le caractère limité des locus et les perturbations postérieures, l'ensemble présente une homogénéité correcte et témoigne d'une des trop rares séries de la fin du Mésolithique en Normandie.
\end{abstract}

\begin{abstract}
An excavation carried out in 2010 on a small road layout close to Gacé (Orne, Normandy) delivered three locus partially preserved attached to the final Mesolithic era. The taphonomic observations of these series included in the silts probably testify for the locus 1 and 2 to in-depth parts trained by the natural agents (burrows, roots...) while the vertical dispersion of the furniture of the locus 3 suggests a formation of the concentration by a phenomenon of colluvial deposition and trapping on the weak relief of the edge of the plate. In fact, some disturbing elements mixed with the Mesolithic series (some modern elements, two arrowheads, schist bracelet, a fragment of polished axe...) but seem to relate to only isolated elements, non significant and lost out of any context of occupation. They testify however that the homogeneity of the series is not completely acquired. The lithic artifacts, cut starting from flint or of poor sandstones of qualities, present a homogeneous series which comes to disturb very modestly some artifacts of the old and final Neolithic era. Because of the raw materials used, the Mesolithic production is directed towards a cutting up where the lamino-lamellate component is limited, pilot of a weak use as supports of tools, and where the production starting from "micronucleus" is frequent. The group of the points is represented by points with gibbeuse truncation, points triangular and thick segmentiforme points. The whole seems to be attached to the complex with reinforcements with gibbeuse truncation (points of Sonchamp, points of Falaise...). In spite of the limited character of the locus and them (modest) posterior disturbances, the unit presents a good homogeneity and testifies to one of the too rare series of the end of the Mesolithic era in Normandy.
\end{abstract}

Mots clés : locus, Mésolithique final, pointe à troncature gibbeuse, pointe triangulaire, retouche inverse rasante, groupes culturels.

Keywords: locus, final Mesolithic era, point with gibbeuse truncation, triangular point.

\footnotetext{
a Inrap, 4 boulevard de l'Europe, 14540 BOURGUEBUS. (emmanuel.ghesquiere@inrap.fr)
} 


\section{LOCALISATION, NATURE ET GÉOMÉTRIE DE L’OPÉRATION}

La commune de Coulmer est située en limite du pays d'Ouche et de la plaine d'Argentan. Elle est établie en contexte de bocage, destiné pour une part importante à l'élevage bovin et dans une moindre mesure à la culture céréalière. La Touques qui coule au pied du site n'est encore qu'un modeste fleuve éloigné d'une dizaine de kilomètres de sa source (fig. 1). Le projet consiste dans l'aménagement d'un nouveau barreau routier rejoignant la RD 14 (route Argentan-Gacé par Exmes) et l'autoroute A 28. L'emprise totale présente une superficie de 9,5 hectares sous la forme d'un tracé linéaire d'un kilomètre sur cent mètres de largeur, qui traverse la basse vallée de la Touques. La fouille concerne une fenêtre de 4432 mètres carrés, près de l'extrémité ouest du barreau (fig. 2). Juste en contrebas du site, la mise en évidence d'une exploitation agricole d'époque moderne (visible sur le cadastre napoléonien) permet d'expliquer les quelques vestiges relevant de cette période découverts sur le site (fragments de tuiles...) ainsi que les résultats des datations ${ }^{14} \mathrm{C}$ réalisées sur les rares petits charbons épars.

\section{ConteXte géologiQue}

Dans la région de Gacé, les terrains font partie intégrante de la bordure occidentale du Bassin parisien à son contact avec le Massif armoricain. Les plateaux y sont constitués des terrains du Jurassique supérieur et du Crétacé inférieur, coiffés de formations résiduelles à silex et de dépôts éoliens. Ils sont en outre entaillés par le réseau hydrographique qui comprend essentiellement des têtes de vallons, du fait des altitudes assez hautes.

\section{Techniques mises en ouvre}

Le décapage a été réalisé à l'aide d'une pelle à chenille équipée d'un godet lisse de trois mètres de longueur. Il a été interrompu après l'enlèvement de la couche de terre végétale et de la semelle de labour, au niveau d'apparition des silex. Les zones de concentration ont alors été isolées sous la forme de trois locus (le locus 2, le plus pauvre est situé dans la zone de tranche ferme de fouille; les deux autres locus dans la tranche conditionnelle). Les locus ont été fouillés différemment suivant leur densité. Les locus 1 et 2 , livrant de 0,2 à 15 pièces au mètre carré, ont été fouillés manuellement par petites passes de 1 à $2 \mathrm{~cm}$, à la rasette ou à la truelle. Un seau sur trois puis un seau sur 10 ont été tamisés dans le but de retrouver d'éventuels petits éléments, sans résultats significatifs. Les artefacts ont été laissés en place et
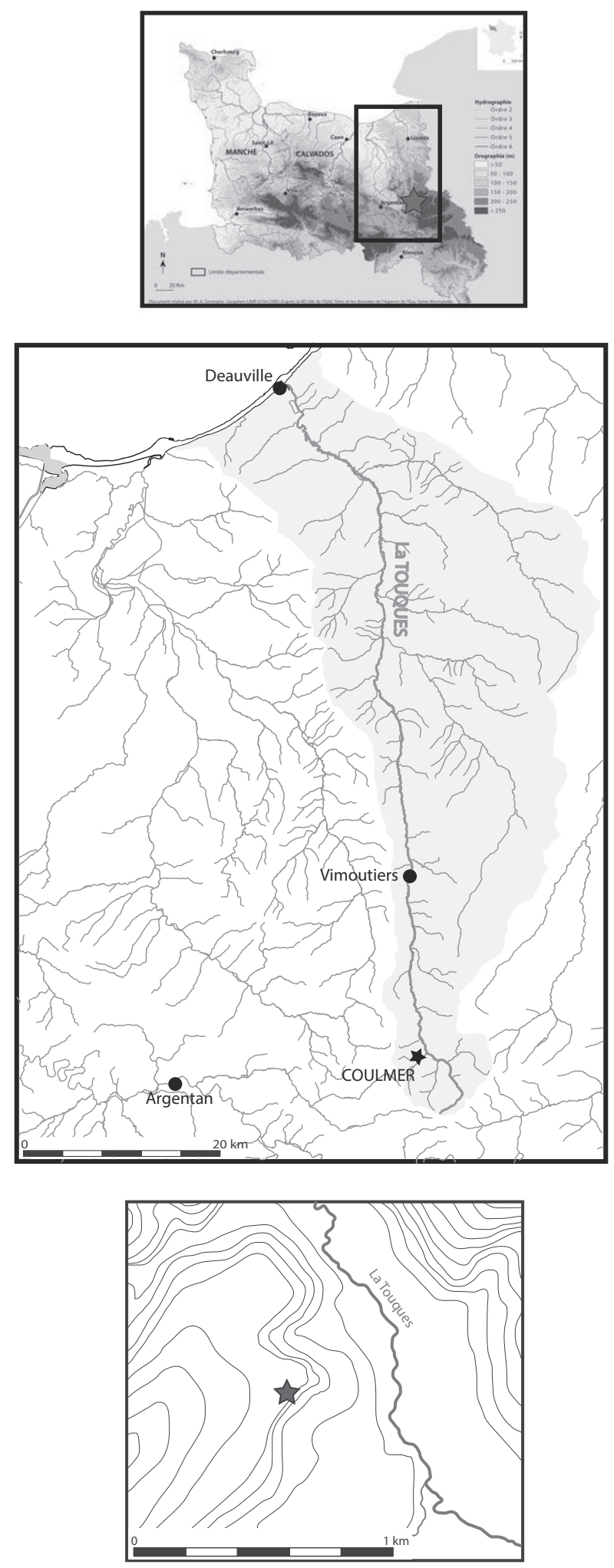

Figure 1 : Coulmer "Beaumont ZH 16 »- Localisation du site sur la vallée de la Touques.

Figure 1: Coulmer "Beaumont ZH 16"-Localization of the site on the valley of the Touques. 


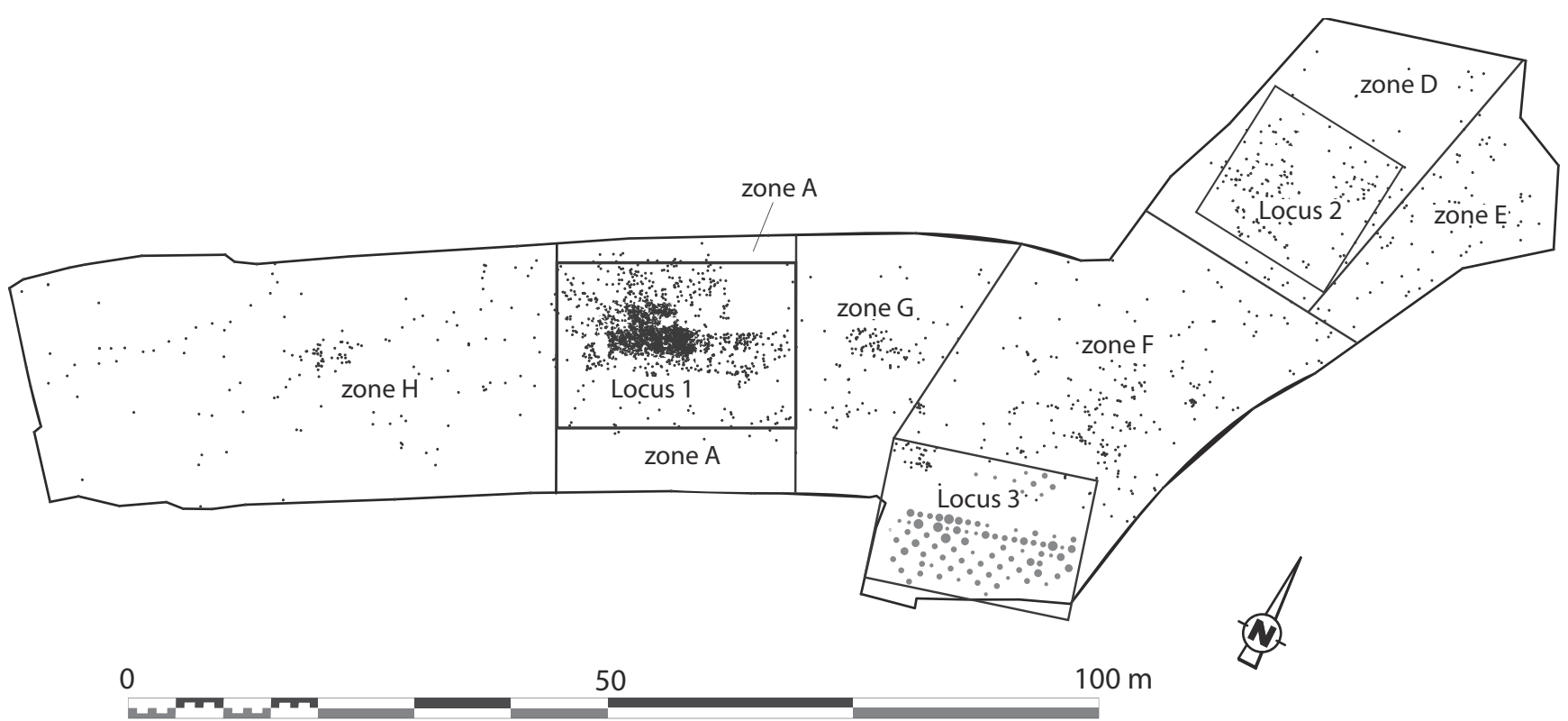

Figure 2 : Coulmer "Beaumont ZH 16 "- Répartition des vestiges dans la fenêtre de fouille avec indication des locus et des zones. Figure 2: Coulmer "Beaumont ZH 16"-Distribution of the vestiges in excavation area with indication of the locus and the zones.

relevés au tachéomètre ( $\mathrm{n}^{\circ}$ de To 1 à To $n$ ) et manuellement au centième ( $\mathrm{n}^{\circ}$ de Loc.x-1 à Loc.x-n). Ils sont immatriculés sur les pièces. Le locus 3, beaucoup plus dense, a été fouillé au piochon léger ou à la truelle, avec relevé des pièces par mètre carré uniquement. En tout, 85 mètres carrés auront été traités manuellement, qui ont livré chacun entre 25 et 1037 vestiges lithiques. La fouille a concerné pour partie la moitié inférieure de la couche de terre végétale et le lambeau de limon brun gris sous-jacent. Le tamisage d'un seau sur deux puis un sur trois a été réalisé dans ce locus. L'ensemble du décapage hors locus a livré des silex plus ou moins dispersés. Tous ont fait l'objet d'un relevé au tachéomètre. Les silex ont ensuite été rassemblés en grandes zones artificiellement attribuées suivant la densité de vestiges (de $\mathrm{A}$ à $\mathrm{H}$ ).

\section{Résultats}

Le décapage de la fenêtre de fouille n'a pas permis de mettre en évidence de structures appartenant à la période mésolithique. L'absence des niveaux de sol d'origine n'aurait permis dans le meilleur des cas de ne retrouver que les structures profondes (Verjux, 2010; Ghesquière, 2010), absentes ici. Seules cinq structures de combustion modernes sont présentes dans le décapage.

\section{LES VESTIGES MÉSOLITHIQUES}

Le décapage de l'ensemble de l'emprise a duré quatre jours. Il a permis de mettre en évidence un premier locus de 1671 pièces lithiques concentrées sur une zone d'une vingtaine de mètres de diamètre. Le second locus, de la même taille, n'a livré que 279 pièces. Le troisième locus, d'une quarantaine de mètres de longueur proposée est composé d'une industrie attribuée principalement au Mésolithique mélangé à un grand nombre de cassons naturels. S'il est riche de 20558 pièces, il n'y a probablement que $25 \%$ des pièces qui soient mésolithiques (d'après un décompte partiel), le reste étant composé de cassons naturels. Le reste du décapage de l'emprise, entre les trois locus, a livré de nombreuses pièces lithiques dispersées, appartenant très probablement à la période mésolithique sur les deux tiers ouest du décapage, et mélangées entre Mésolithique et " Néolithique " dans le tiers est?

\section{Le Locus 1}

\section{Introduction}

Ce locus se situe en limite de concentration sur la tranchée 27 de diagnostic (Ghesquière, 2009), aligné sur son côté sud, qui présentait un léger pic de présence de silex taillés. Il est apparu au décapage sous la forme d'une concen- 
tration de vestiges de 150 mètres carrés environ et d'une couronne de mobilier dispersé de 800 mètres carrés autour (fig. 3). Le mobilier lithique découvert regroupe 1786 artefacts. Il se décompose en 722 éléments de plus de $1,5 \mathrm{~cm}$ de longueur et 1064 esquilles, auxquels il faut ajouter deux plaquettes de grès, six fragments de percuteurs (quatre en silex, un en grès), une "plaquette " de schiste, deux pointes de flèche néolithiques et une pierre à fusil moderne. L'outillage rassemble cinquante outils communs et seize armatures. La surface relativement concentrée $\left(150 \mathrm{~m}^{2}\right)$ et la zone de dispersion attenante $\left(800 \mathrm{~m}^{2}\right)$ ne rassemblent que les restes modestes d'une occupation arasée, avec en moyenne dix artefacts par mètre carré dans la zone de concentration.

\section{Position stratigraphique des vestiges}

Les vestiges ont été découverts sitôt la couche de terre végétale et la couche intermédiaire enlevée (" semelle de labour ", $5 \mathrm{~cm}$ de puissance). Les artefacts présents dans la terre végétale sont rares et n'ont pas été ramassés lors de la fouille. Le mobilier est inclus dans une couche de limon brun orangé bioturbée, surmontant le niveau argileux orangé stérile. D'un point de vue taphonomique, le mobilier n'est pas en place dans cette couche. Il résulte très probablement d'un enfouissement par les agents naturels, végétaux éventuellement mais surtout animaux, qui ont entraîné le mobilier lithique depuis un niveau d'occupation structuré en surface du sol (depuis lors érodé et colluvionné) jusqu’au niveau non remaniée par les labours. L'ensemble du mobilier doit donc être considéré comme un reliquat aléatoire d'un niveau domestique. L'enfouissement du mobilier par les agents naturels a, de fait, affecté en priorité les éléments de petite taille; $60 \%$ de la série est constituée par les esquilles. La principale pierre d'achoppement concernant un enfouissement du mobilier depuis un sol d'habitat est la possibilité de mélange avec des séries postérieures. Les témoins d'occupation modernes sont ainsi présents (en très faible nombre) à tous les niveaux de la couche à silex. De même, la présence de deux pointes de flèche néolithiques et d'une pierre à fusil témoigne d'un mélange évident. Toutefois, les vestiges clairement associés aux périodes postérieures sont des pièces retrouvées de façon récurrente hors des contextes domestiques et perdus/brisés sur le lieu de leur utilisation (pointes de flèche, hache polie, fragments de lames régulières...). L'ensemble de la série lithique suggère une homogénéité de la grande majorité, sinon de la presque totalité des vestiges.

\section{Matières premières}

Plusieurs matières premières distinctes ont été mises en évidence sur le locus 1 . La plupart est constitué du silex du Pays d'Auge ( $74 \%$ de la série), disponible à quelques kilomètres à l'est du gisement. Ce silex présente un cortex fin et une variété importante de faciès, tantôt gris, tantôt ocre. Ses aptitudes au débitage sont dans le cas présent réduites. Il est très fracturé et se détache fréquemment sous forme de cassons polyédriques. De nombreuses cavités internes rendent les blocs presque inexploitables de manière récurrente. Quelques blocs sont également très grenus, parfois poreux. La taille réduite des déchets de taille suggère des rognons disponibles de faible dimension.

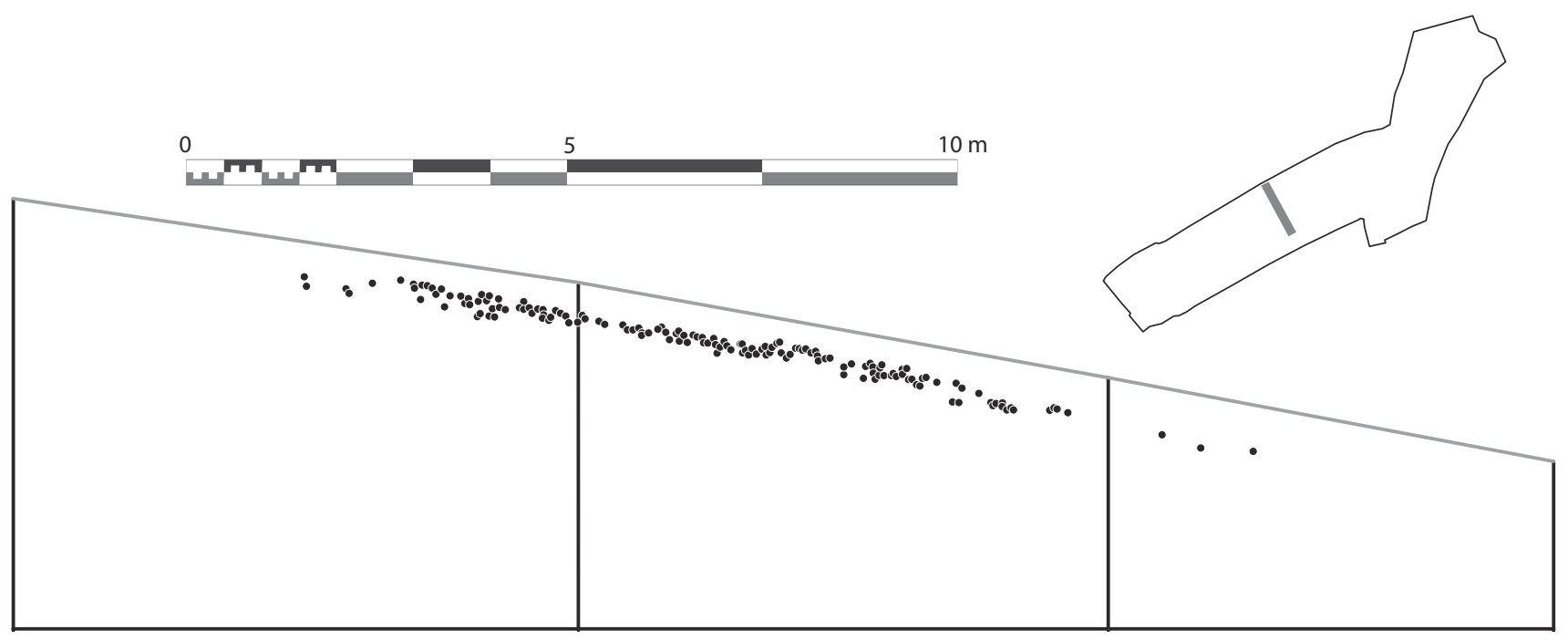

Figure 3 : Coulmer « Beaumont ZH 16 »-Répartition stratigraphique des vestiges du locus 1, à partir des pièces présentes dans une bande de trois mètres de largeur, orientée ouest-est.

Figure 3: Coulmer "Beaumont ZH 16" - Stratigraphic distribution of the vestiges of the locus 1, starting with objects located in a band of 3 meters width, orientation west-east. 
Un autre silex se distingue par ses bonnes aptitudes à la taille. Il présente un cortex fin non roulé, une couleur noire mate mouchetée de points blancs. Ce silex est également originaire du Pays d'Auge (0,7\% de la série, mais $12 \%$ de l'outillage). Les gisements présentant une bonne qualité ont été identifiés en quantité à Deauville, sur l'estuaire de la Touques (fig. 1). Sa présence est toutefois effective à proximité du site (avec des qualités de blocs variables), contrastant avec l'ensemble des autres blocs de silex, voire un peu plus au nord vers Vimoutiers.

Enfin, deux éclats et un fragment de lame sont en silex bathonien, provenant au plus près de la plaine d'Argentan, à une trentaine de kilomètres à l'ouest du site.

Le reste du mobilier est représenté par des grès à ciment siliceux, de couleur grise, se présentant sous forme de plaquettes plus ou moins épaisses (24\% de la série). Leurs couleurs varient d'un gris clair légèrement bleuté et un aspect mat à une couleur gris foncé (parfois bordé de passées ferrugineuses de couleur bordeaux) et un aspect satiné, rejoignant alors la dénomination de " grès lustré ». Les aptitudes à la taille de la première catégorie de grès, presque exclusive, est moyenne à médiocre, avec également production de cassons importante. La seconde catégorie, le "grès lustré ", de bien meilleure qualité, semble permettre une production (de supports allongés) correcte, mais les vestiges sont trop peu fréquents pour en juger. Quelques éclats de quartz blanc témoignent également d'essais sur une matière presque inapte ici au débitage mésolithique (cassons parallélépipédiques). La provenance des grès n'est pas connue, mais comme pour les silex, sa médiocre qualité laisse penser à une origine locale.

La qualité très moyenne des matériaux utilisés dans le cadre du débitage sur le locus 1 reflète une faible disponibilité de la matière première pour les Mésolithiques. Pourtant, le silex est très abondant dans les argiles sub-affleurantes à proximité du gisement. Il est possible que le couvert végétal ne permette pas la découverte des blocs qui étaient accessibles uniquement dans les chablis résultant de la verse des arbres. Par ailleurs, il semble que les gisements de la forêt de Gouffern (Leroy, 1991) ou de Vimoutiers aient été pour eux hors de leur " territoire de circulation ».

\section{Débitage}

\section{L'industrie en silex (fig. 4)}

Le débitage du silex est orienté de manière très préférentielle vers la production d'éclats; la moitié de l'assemblage est ainsi constitué d'éclats de plein débitage. La seconde dominante est constituée par les cassons (13\%), puis enfin par les supports allongés (lames/lamelles : $4 \%$ ) et éclats laminaires (3\%). Les nucléus à éclats ou à supports allongés et les blocs testés constituent la majorité du reste de la série $(13 \%)$. Il n'y a pas de déséquilibre fondamental entre la production sur silex et sur grès, l'une comme l'autre sont dominées par la production de produits courts dans l'assemblage. Ce déficit en produits allongés, ces derniers considérés comme une des caractéristiques techniques de la période, est cependant contrebalancé par la présence importance de nucléus à lamelle ( 24 pièces) et la moindre représentation de nucléus à éclat (18 pièces et 12 blocs testés ne comportant que quelques enlèvements).

La production d'éclats est effectuée à partir de nucléus globuleux, offrant de multiples plans de frappe. Les blocs supports, tels qu'on les trouve dans les formations superficielles au niveau local, sont toujours fragmentés et offrent donc des surfaces planes directement exploitables comme plan de frappe. Les pièces d'entame et de sous-entame sont donc peu nombreuses. Presque la moitié des éclats présentent toutefois un reliquat de zone corticale, témoins de l'exploitation tournante (nucléus à multiples plans de frappe) de petits rognons. Les stigmates de percussion témoignent de l'usage du percuteur dur. Quatre percuteurs en silex et deux percuteurs en grès découverts dans le locus ont pu participer à cette phase de débitage. La production consiste principalement en éclats courts voire larges, utilisés comme supports de grattoirs et d'éclats retouchés. Les éclats de grande dimension sont rares (fig. $5, n^{\text {os }} 22$ et 23 ) et fréquemment utilisés comme support d'outil. Les petits éclats, majoritaires, ont été dans l'ensemble peu utilisés. Certains éclats larges et minces ont pu être préférentiellement recherchés pour le façonnage d'armatures, souvent presque aussi larges que hautes (fig. 7, $\mathrm{n}^{\text {os }} 1,2$ et 6 ).

La production lamino-lamellaire est extrêmement discrète. Les produits se limitent à six lames entières ou fragmentées, quatorze lamelles entières ou fragmentées et éventuellement douze éclats laminaires. Les témoins indirects tels que les nucléus sont de fait aussi nombreux (24 pièces). Parmi les rares lames mises au jour, certaines sont irrégulières et épaisses (fig. $5, \mathrm{n}^{\circ} 1$ ), mais plusieurs témoignent de beaucoup plus de régularité (fig. $5, \mathrm{n}^{\text {os }} 2$ et 7), une seule pouvant être attribuée à ce que l'on appelle le style Montbani (fig. 7, n ${ }^{\circ} 15$ ). Les rares lamelles présentes sont courtes ou fragmentaires. Une seule peut sans hésitation se placer dans une production régulière (fig. 5 , $\mathrm{n}^{\circ} 6$ ). Les nucléus présentent des négatifs d'enlèvements lamellaires avec un nombre toujours conséquent de produits extraits, même s'ils ne sont pas tous très réguliers (fig. 6, nos 5 et 6). Leur morphologie est caractéristique du Mésolithique, avec la présence de deux nucléus unipolaires, deux nucléus pyramidaux et trois nucléus croisés. Lorsque la taille des rognons le permet, l'enlèvement d'éclats d'avivage peut être observé (fig. $5, n^{\circ} 4$; fig. $6, n^{\circ} 5$ ). 


\begin{tabular}{|c|c|c|c|c|c|c|c|c|c|c|c|}
\hline \multicolumn{12}{|c|}{ COULMER 2010 Locus 1} \\
\hline & \multicolumn{4}{|c|}{ silex pays auge } & \multicolumn{3}{|c|}{ silex noir mouch } & \multirow{2}{*}{\begin{tabular}{|c|} 
grès lustré \\
$\mathrm{S}$
\end{tabular}} & \multicolumn{2}{|c|}{ autre silex } & \multirow[t]{2}{*}{ TOT } \\
\hline & $\mathrm{S}$ & $\mathrm{C}$ & $\mathrm{B}$ & $\mathrm{BC}$ & $\mathrm{S}$ & $\mathrm{C}$ & $\mathrm{B}$ & & $\bar{S}$ & $\mathrm{C}$ & \\
\hline éclat d'entame & & 15 & & & & & & & & & 15 \\
\hline éclat de sous-entame & & 10 & & & & & & & & & 10 \\
\hline éclat indéterminé & 10 & 19 & & & 1 & & & 12 & & & 42 \\
\hline éclat de plein débitage & 133 & 102 & 7 & 9 & 7 & 1 & & 131 & & 2 & 392 \\
\hline lame & 2 & & & & & & & & & & 2 \\
\hline fragment de lame & 4 & & 2 & & & & & 1 & 1 & & 8 \\
\hline lamelle & 4 & & & & & & & & & & 4 \\
\hline fragment de lamelle & 7 & 3 & & & 1 & & & 4 & & & 15 \\
\hline éclat laminaire & 7 & 3 & 3 & & & & & 8 & & & 21 \\
\hline pièce d'avivage & 1 & & & & & & & 1 & & & 2 \\
\hline casson & 34 & 27 & & 1 & & & & 34 & & & 96 \\
\hline débris brulé & & & 15 & 7 & & & & & & & 22 \\
\hline nucléus unipolaire & & 3 & & & & & & 9 & & & 12 \\
\hline nucléus pyramidal & & 2 & & & & & & 5 & & & 7 \\
\hline nucléus croisé & 2 & 3 & & & & & & & & & 5 \\
\hline nucléus à éclats & 5 & 9 & & & & & & 4 & & & 18 \\
\hline galet testé & & 10 & & & & & & 3 & & & 12 \\
\hline micro-nucléus & 12 & 10 & & 1 & & & & 16 & & & 39 \\
\hline Total débitage & 221 & 216 & 27 & 18 & 9 & 1 & & 228 & 1 & 2 & 722 \\
\hline autre esquille & 538 & 209 & 69 & 15 & 2 & & & 229 & 2 & & 1064 \\
\hline Total débitage avec esquilles & 759 & 425 & 96 & 33 & 11 & 1 & & 457 & 2 & 2 & 1786 \\
\hline \multicolumn{12}{|l|}{ Outillage } \\
\hline armature & 3 & & & & & & & 3 & & & 6 \\
\hline fgt armature? & 8 & & & & & & & 3 & & & 11 \\
\hline grattoir sur éclat & 1 & 1 & & & 3 & & & 2 & & & 7 \\
\hline grattoir sur lame & 1 & & & & & & & & & & 1 \\
\hline grattoir denticulé & & & & & 1 & & & & & & 1 \\
\hline grattoir unguiforme & 1 & 2 & & & & & & & & & 3 \\
\hline racloir & 1 & & & 1 & & & & & & & 2 \\
\hline burin sur lame tronquée & & & & & & & & & 1 & & 1 \\
\hline lamelle à retouche part. reg. & 1 & & & & & & & & & & 1 \\
\hline éclat mince retouché & 5 & 2 & & & 1 & & & 2 & & & 10 \\
\hline éclat épais retouché/denticulé & 1 & 2 & & & 1 & & & 4 & & & 8 \\
\hline éclat tronqué & & & & & 1 & & & & & & 1 \\
\hline macro-outil & & & & & & 1 & & & & & 1 \\
\hline débris d'outils communs & 1 & & & & & & & & & & 1 \\
\hline limace & & 1 & & & & & & & & & 1 \\
\hline \multicolumn{12}{|l|}{ boucharde } \\
\hline coche & 3 & 4 & & & & & & 4 & & & 11 \\
\hline Total Outillage & 26 & 12 & & 1 & 7 & 1 & & 18 & 1 & & 66 \\
\hline percuteur & 4 & & & & & & & 2 & & & 6 \\
\hline plaquette schiste & & & & & & & & & 1 & & 1 \\
\hline plaquette grès lustré & & & & & & & & 1 & & & 1 \\
\hline pointe flèche néolithique & & & & & & & & & 2 & & 2 \\
\hline pierre à fusil & & & & & & & & & 1 & & 1 \\
\hline S : sain, C : cortical, B : brûlé & $c: b_{1}$ & rûlé c & tica & & & & & & & & \\
\hline
\end{tabular}

Figure 4 : Coulmer "Beaumont ZH 16 »Tableau de décompte de l'assemblage du locus 1. Figure 4: Coulmer "Beaumont ZH 16"Inventory of the artifacts of the locus 1.
Les micro-nucléus sont au nombre de vingt et un. Ce sont des pièces plus ou moins cubiques, de 10 à $25 \mathrm{~mm}$ de hauteur de flanc. Ils portent à leur surface les négatifs d'enlèvements de très petits modules, généralement allongés ou lamellaires, qui n’ont pas de rôle évident comme éven- tuel support d'outils (les armatures de la série sont rarement pygmées, jamais hyper-pygmées). Comme pour le reste de l'assemblage, près de la moitié des pièces présente des reliquats de zone corticale, qui pourrait témoigner de la réduction à l'extrême d'un nucléus à éclat ou à lamelle. 

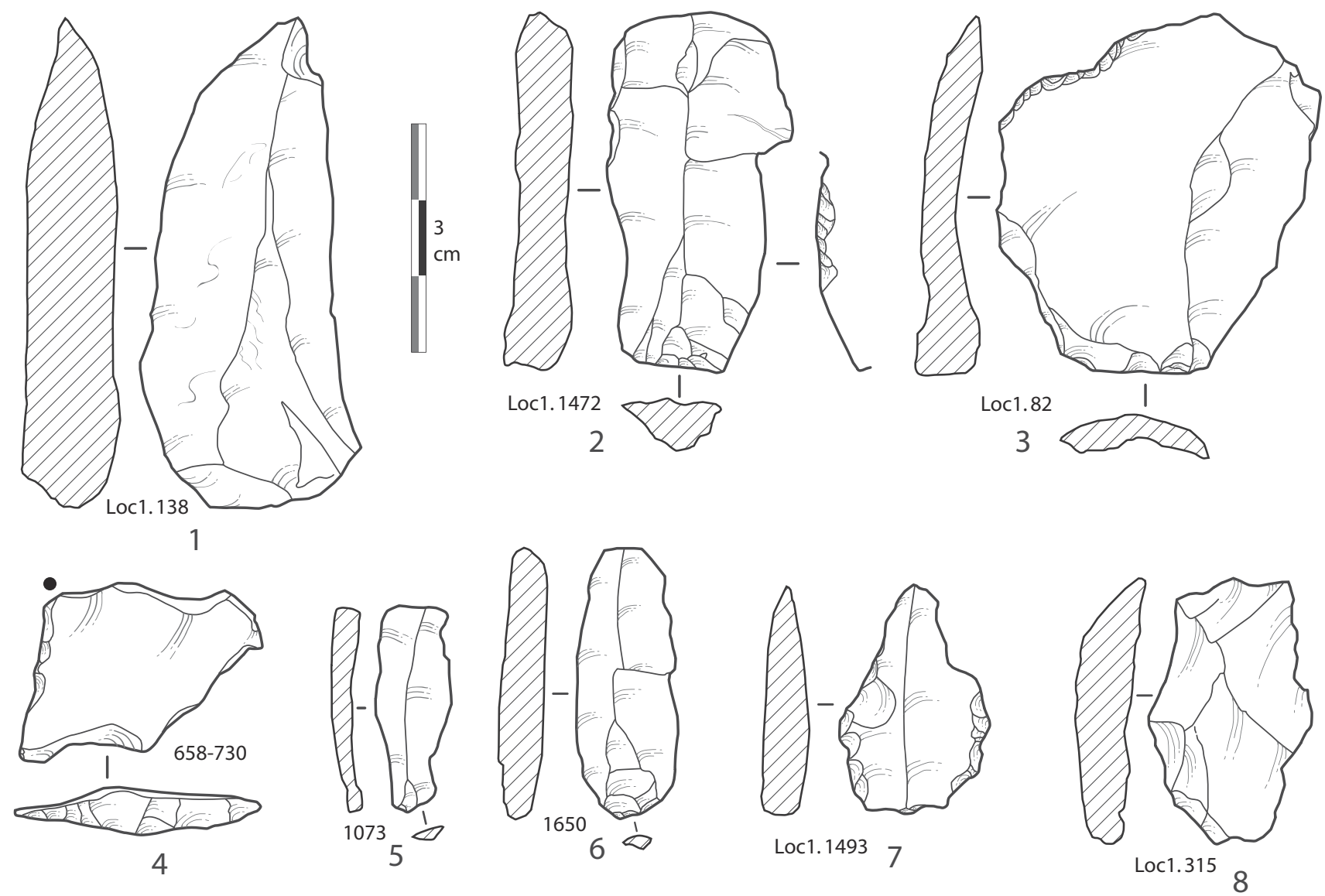

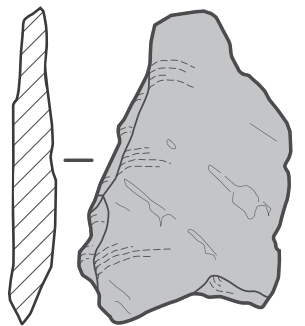

658-730 9

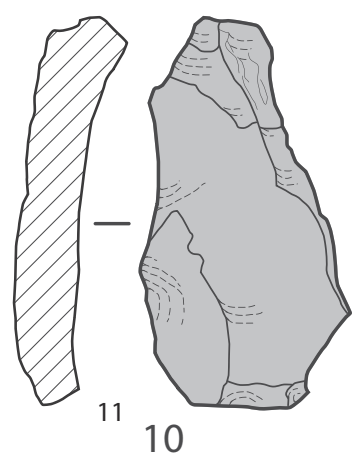

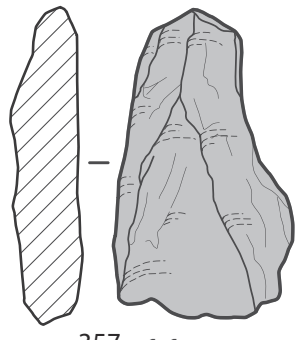

35711
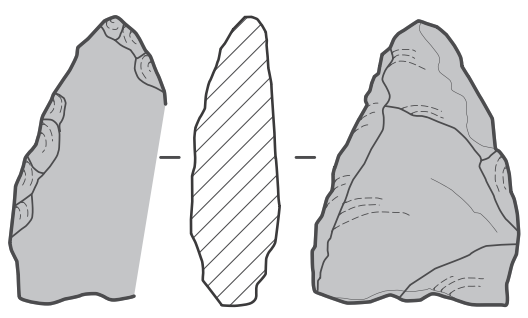

1335
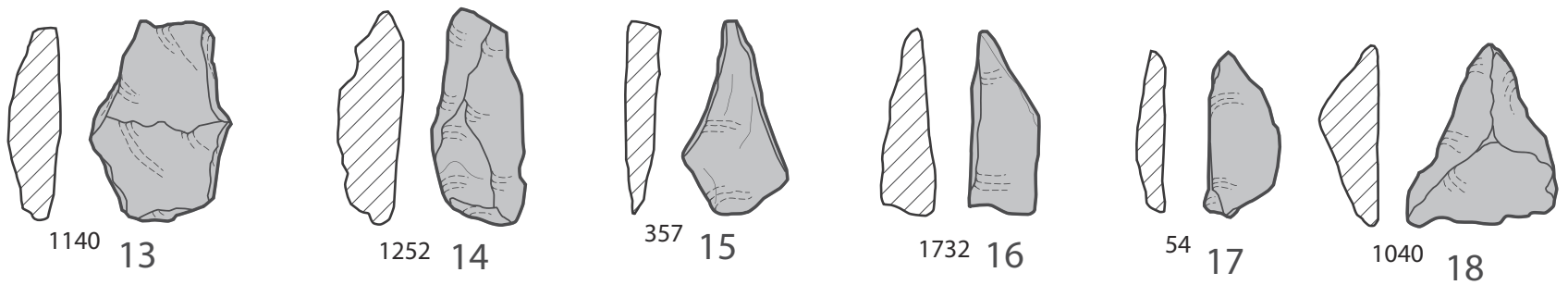

Figure 5 : Coulmer «Beaumont ZH 16 »- Débitage du locus 1 - 1, 2 : lames, 3 : éclat mince retouché, 4 : éclat d'avivage, 5, 6 : lamelles, 7 : fragment de lame retouchée, 8 : éclat technique, 9 à 18 : éclats et éclats laminaires en grès.

Figure 5: Coulmer "Beaumont ZH 16" - Production of the locus 1 - 1.2: blades, 3: retouched blade, 4: scale from reviving, 5.6: strips, 7: fragment from improved blade, 8: technical chip, 9 to 18: sandstone flakes. 


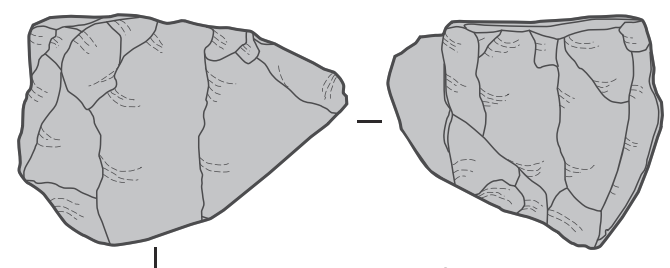

Loc 1.1352

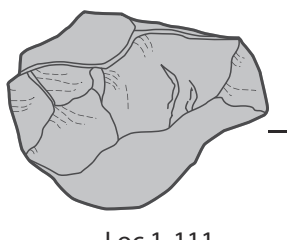

Loc 1.111
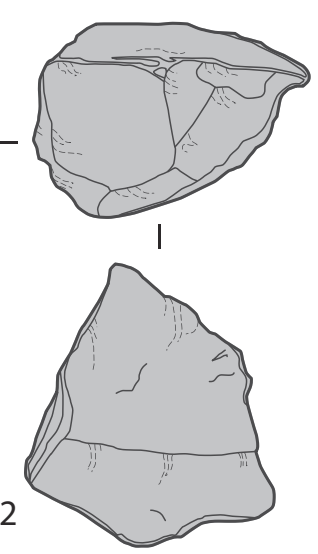
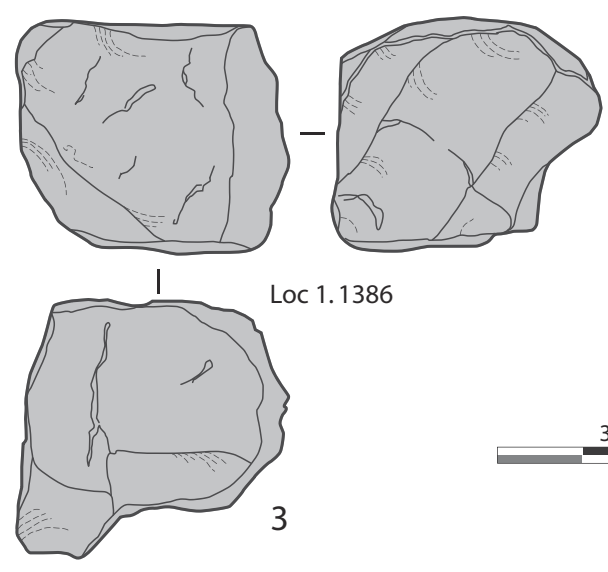

$3 \mathrm{~cm}$
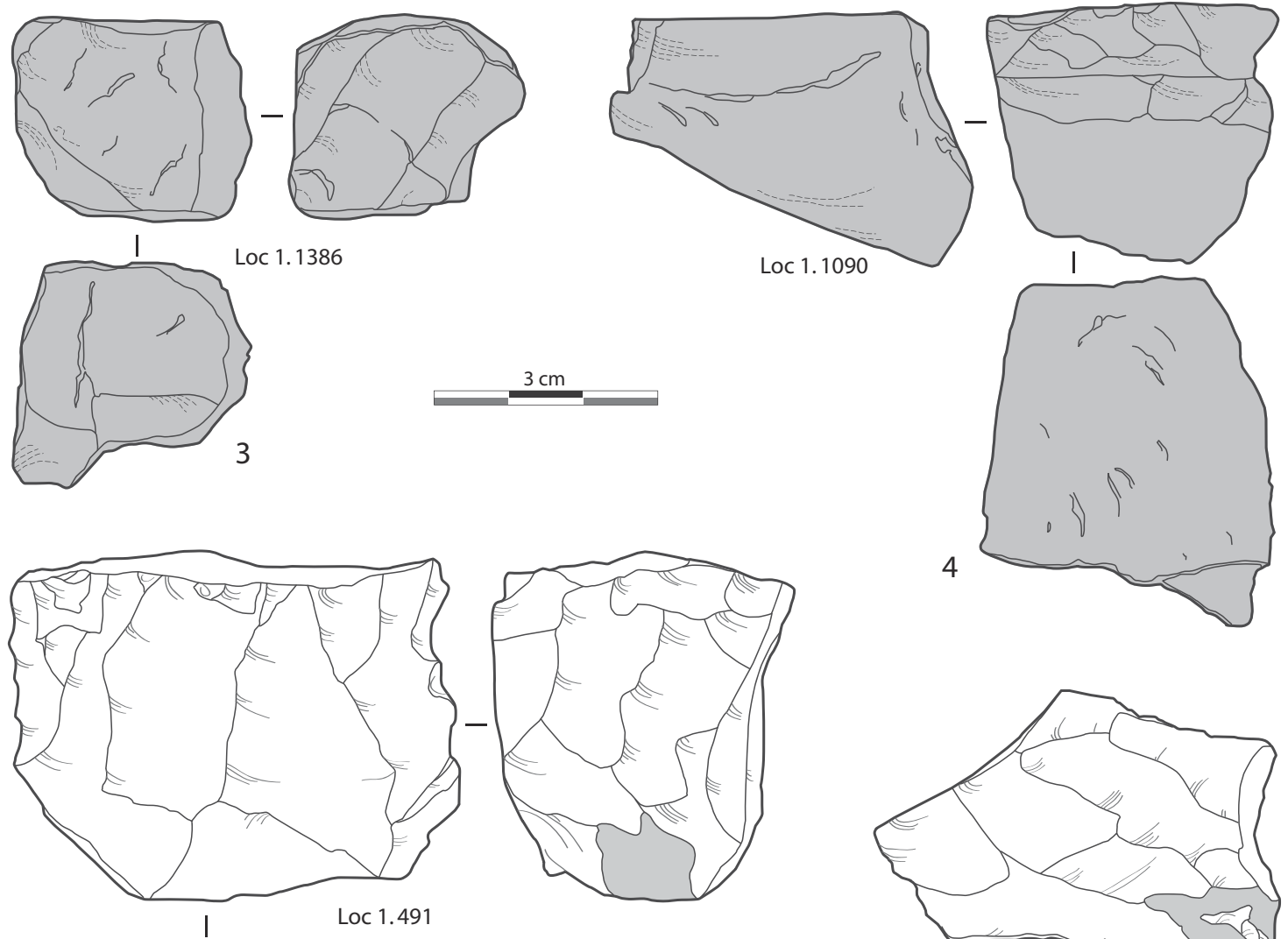

4
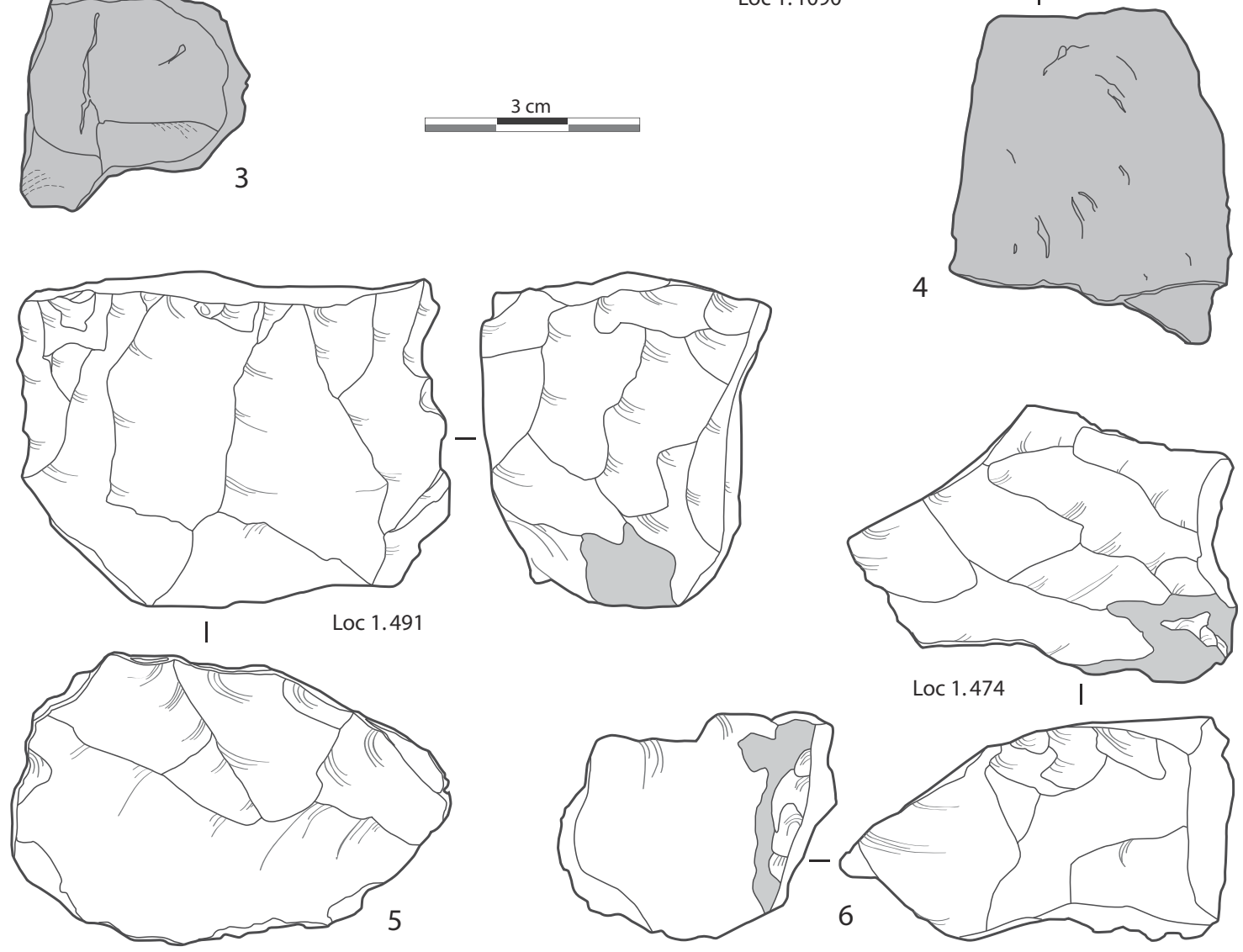

Figure 6 : Coulmer "Beaumont ZH 16 " - Débitage du locus 1 - 1 à 3 : nucléus à lamelle en grès, 4 : bloc de grès testé et abandonné à cause d'une fissure, 5 : nucléus pyramidal, 6 : nucléus croisé.

Figure 6: Coulmer "Beaumont ZH 16"-Production of the locus 1 - 1.3: sandstone bladelet nucleus, 4: block of sandstone tested and abandoned because of a crack, 5: pyramidal nucleus, 6: crossed nucleus. 
Le nombre d'esquilles est important (une pièce sur deux). Une part importante de ces pièces est corticale, témoin que leur production résulte de l'ensemble des phases du débitage. Nombreuses également sont celles provenant des phases de production des « micro-nucléus ».

\section{L'industrie en grès}

Le débitage du grès est orienté vers la production d'éclats minces et plus ou moins allongés. La matière première, comme le silex de qualité moyenne à médiocre, entrâne la production de pièces fréquemment à section prismatique, ou au contraire souvent à la limite de l'esquille. Tandis que les pièces épaisses ont été utilisées comme supports d'éclats retouchés, les plus minces et régulières ont pu être utilisées comme supports de coche ou d'armature.

La matière étant de qualité assez moyenne, très fissurée en particulier, le nombre de cassons prismatiques est important. Des éclats assez réguliers ont toutefois été produits, présentant un caractère allongé dans moins de $10 \%$ des cas (fig. 5 , $\mathrm{n}^{\text {os }} 9$ à 12). Les stigmates de débitage sont très difficiles à lire sur cette matière première grenue. Les bulbes sont toujours très peu marqués voire absents. La technique de la percussion directe dure est privilégiée ici, mais des expérimentations seraient nécessaires. Les nucléus qui résultent de ce type de débitage sont unipolaires, le débitage s'opérant à partir d'une table naturelle plate, résultant du bris d'anciennes formations tabulaires. Certains nucléus, qualifiés de micro-nucléus (fig. $6, n^{\circ} 2$ ), présentent lors de leur abandon les négatifs d'enlèvements de petites esquilles. D'autres blocs, presque bruts, ont été rapidement abandonnés en raison d'une fissure interne (fig. 6, $\mathrm{n}^{\circ}$ 4). Dans l'ensemble, et comme pour le matériau en silex, seul le rebut semble abandonné ici, en dehors des quelques outils. Cela rejoint la question déjà évoquée d'une pénurie de matière première de qualité et une surexploitation des produits débités de qualité.

Quelques rares supports témoignent d'une production que l'on peut qualifier de lamellaire (fig. $5, \mathrm{n}^{\circ} 6$ ). Plus nombreux en revanche sont les nucléus qui livrent les négatifs d'une production lamellaire régulière, avec une production finale de supports de très petit module (fig. $6, \mathrm{n}^{\text {os }} 1$ et 3 ). Même si, ici aussi, les stigmates de débitage sont très peu marqués, la percussion directe (tangentielle) dure est proposée à titre d'hypothèse. Comme pour la production d'éclats, le débitage s'organise directement à partir d'un plan de frappe naturel plan (surface de plaquette).

Les esquilles constituent un artefact en grès sur deux. Dans le cadre de la fouille, elles ont fait l'objet d'une attention particulière en raison de la petitesse générale de l'outillage mésolithique. Elles résultent pour une part de la production des «micro-nucléus ».

\section{L'outillage}

Sur les soixante-six outils mis en évidence, quatre dominantes ressortent, même si l'on ne peut pas considérer l'échantillon comme statistiquement représentatif. Loutillage de fond commun se partage entre quinze éclats retouchés ou denticulés, onze supports à coche et dix grattoirs. La série des armatures se monte à dix-sept pièces, parmi lesquelles onze présentent un caractère trop fragmenté pour être certain de leur destination.

Les grattoirs sont représentés par cinq exemplaires simples sur éclat (fig. $7, \mathrm{n}^{\circ} 17$ ), pour lesquels la retouche semiabrupte concerne exclusivement la partie distale de la pièce; un grattoir sur fragment proximal de lame (fig. $7, n^{\circ} 15$ ) est dans ce cas; un gros grattoir denticulé (fig. $7, \mathrm{n}^{\circ} 16$ ) est confectionné sur un gros éclat par une retouche semiabrupte profonde non régularisée, avec également quelques enlèvements inverses. Enfin, trois petits grattoirs, classés dans la catégorie des unguiformes (peut-être un peu abusivement) complètent la catégorie (fig. $7, \mathrm{n}^{\text {os }} 10,11$ et 14 ). Ils ont été réalisés à partir de petits éclats/esquilles de 5 à $7 \mathrm{~mm}$ d'épaisseur, voire sur un bout de lamelle épaisse pour l'un d'entre eux (fig. $\left.7, n^{\circ} 10\right)$. Ils portent une retouche semiabrupte directe qui concerne l'extrémité distale de la pièce ainsi que le côté gauche de chacun d'entre eux.

Les éclats retouchés/denticulés sont principalement représentés par des petits éclats minces présentant une retouche marginale (quelques centimètres de longueur de front), résultant de l'usage (outils a posteriori) ou d'un aménagement préalable à l'emploi (fig. $5, \mathrm{n}^{\text {os }} 3$ et 7 ; fig. $7, \mathrm{n}^{\circ} 8$ ). Quelques éclats épais denticulés sont présents, mais leur réalisation est peu soignée. Les coches ne sont jamais ni jointives, ni très régulières dans leurs délinéations.

Les supports à coche (fig. $7, \mathrm{n}^{\text {os }} 9,12$ et 13 ) sont indifféremment réalisés sur éclat court ou allongé (voire sur lamelle, fig. $\left.7, n^{\circ} 13\right)$; représentatif de l'ensemble de la série, les petits éclats sont privilégiés. Les grès semblent assez nombreux par rapport à leur représentation générale; les caractéristiques particulières du matériau (grenu et tenace) y sont éventuellement pour quelque chose. Tous les supports ne portent qu'une coche unique, désaxée sur une des extrémités. Elle est en règle générale peu profonde $(0,2 \mathrm{à} 0,4 \mathrm{~cm})$ et peu large $(1$ à $2 \mathrm{~cm})$. Certains supports à coche pourraient être des ébauches d'armature (fig. $7, \mathrm{n}^{\text {os }} 9$ et 12), la plupart toutefois sont nettement trop épais et/ou trop larges (fig. 7, $\mathrm{n}^{\circ} 13$ ).

Les deux racloirs sont réalisés sur des éclats peu réguliers; la retouche occupe un des bords latéraux des deux pièces. Elle est semi abrupte et détermine un front peu régulier.

Le burin sur lame est réalisé aux dépens d'une lame en silex bathonien fin, dont les stigmates de débitage évoquent la percussion indirecte : talon large et épais, bulbe bombé 

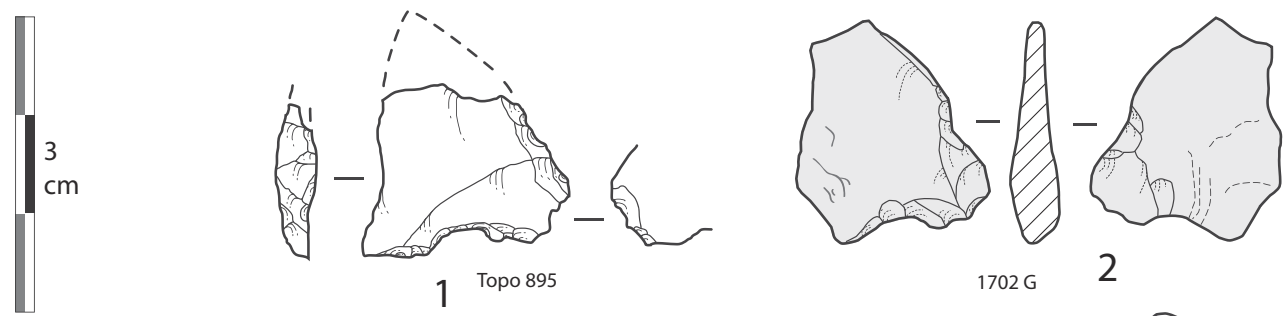

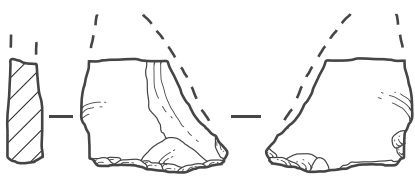

3

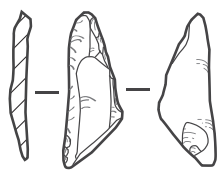

Loc1.1072 7

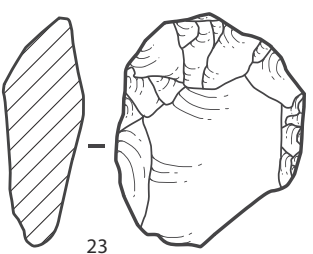

11

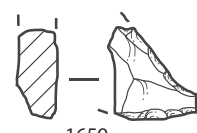

4

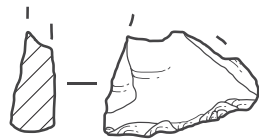

440

5

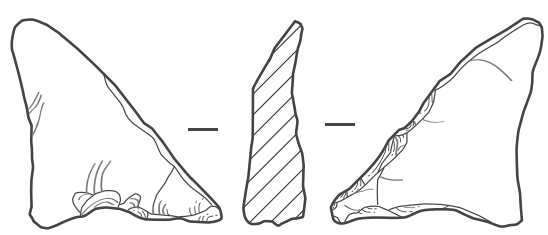

6 Topo 187
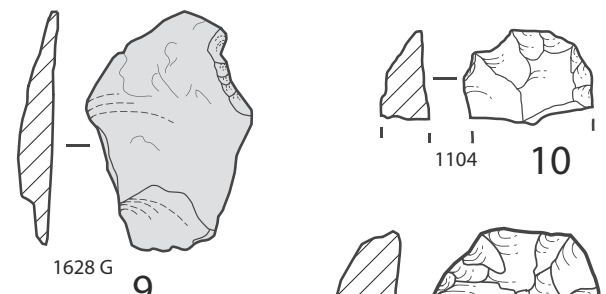

$8^{61}$

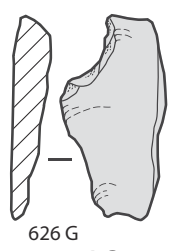

12

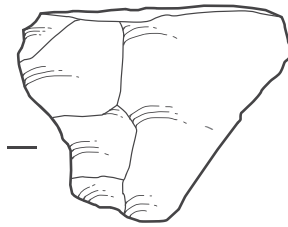

61
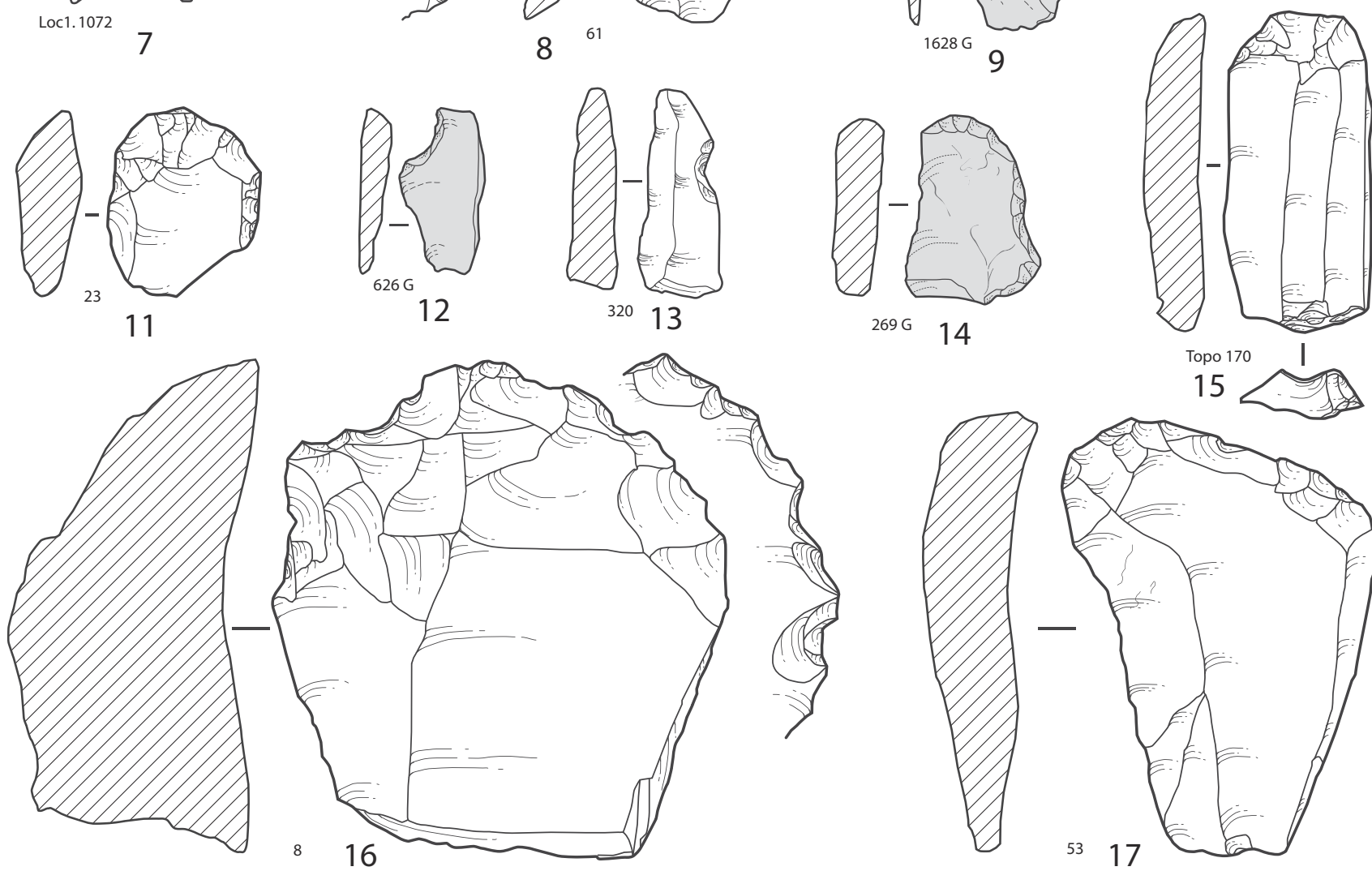

14

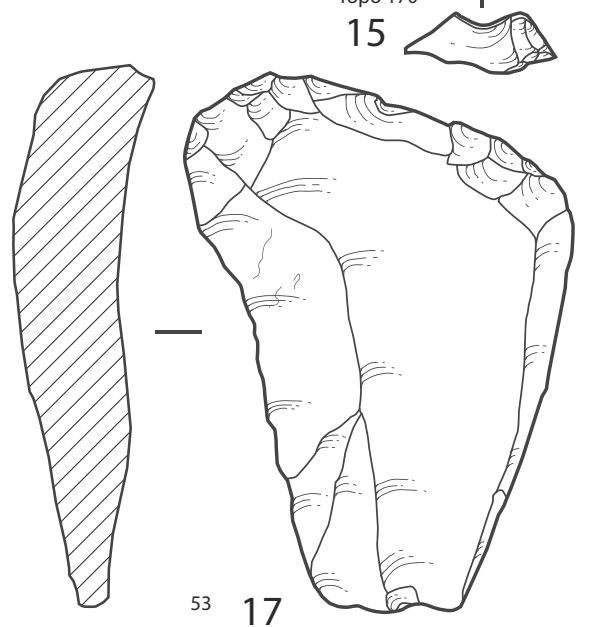

Figure 7 : Coulmer «Beaumont ZH 16 »-Outillage du locus 1 - 1 et 2 : pointes à troncatures gibbeuses, 3 : fragment de pointe à troncatures gibbeuses?, 4 : triangle scalène, 5 : triangle de Chateauneuf (mobilier dispersé zone $\mathrm{H}$ ), 6 à 8 : fragments de pointes triangulaires, 9 : ébauche d'armature tranchante?, 10 : fragment d'armature, 11,13,14,15, 19, 20 : supports à coche, 12 : éclat mince retouché, 16 à 18 : grattoirs unguiformes, 21 : nucléus en bout de lame, 22 : grattoir denticulé, 23 : grattoir simple sur éclat.

Figure 7: Coulmer "Beaumont ZH 16" - Tools of the locus $1-1$ and 2: points with gibbeuses truncations, 3: fragment of a point with gibbous truncations?, 4: triangular scalene, 5: Chateauneuf triangle (dispersed elements in zone H), 6 to 8: fragments from triangular points, 9: outline of bladed armature?, 10: point fragment, 11,13,14,15,19,20: notched blanks, 12: improved flake, 16 to 18: unguiform scrapers, 21: blade nucleus, 22: denticulated scraper, 23: simple scraper on flake. 
et court, support régulier à trois pans, épaisseur moyenne et constante. Plusieurs chutes de burin ont été détachées à partir d'une troncature rectiligne. Une retouche mineure d'au moins un des tranchant a été réalisée avant détachement pour servir d'arête-guide.

Le reste de l'outillage se compose d'outils représentés chacun par une seule pièce. Un gros éclat tronqué est réalisé aux dépens d'un support laminaire. Il porte une troncature abrupte de son extrémité distale (et partiellement de son tranchant gauche) et une retouche inverse plate profonde de sa base. Typologiquement, il pourrait se placer dans la catégorie des couteaux à dos. La retouche de la base suggère un emmanchement longitudinal de la pièce. Un éclat àretouche directe de tout le bord ( " limace»), un macro-outil denticulé et un débris d'outil inidentifiable complètent la série.

\section{Les armatures}

La série est faible puisqu'elle ne repose que sur six individus incontestables et onze qui prêtent à discussion. Elle se partage en trois types distincts.

Le premier est représenté par deux pointes à troncatures gibbeuses, l'une réalisée sur un éclat mince en silex (fig. 7, $\mathrm{n}^{\circ} 1$ ) et l'autre sur un éclat mince en grès (fig. $7, \mathrm{n}^{\circ} 2$ ). La retouche est semi-abrupte et irrégulière. Une retouche inverse rasante est présente sur chacune des pièces. Elles sont trapues et peuvent être attribuées à des formes trapézoïdales. Cependant, elles appartiennent aux formes de pointes dites " évoluées " à troncature gibbeuse qui sont une des caractéristiques du Mésolithique interrégional (pointes de Sonchamp, pointes de Falaise et armatures à éperon). Les caractères morphologiques des deux exemplaires de Coulmer les apparentent davantage à certaines des pointes de Sonchamp, peut-être parmi les exemplaires les moins typiques (fig. $7, \mathrm{n}^{\text {os }} 11$ et 21 in Girard, 1995). Une pièce fragmentaire, dont la retouche est directe semi-abrupte, a été rattachée avec plus ou moins de certitude à la même catégorie des pointes à troncature gibbeuse trapues.

La seconde catégorie est composée d'un seul exemplaire. Il s'agit d'un petit triangle scalène (fig. $7, \mathrm{n}^{\circ} 7$ ) réalisé sur une lamelle peu épaisse. La retouche est directe et abrupte. La base présente une retouche inverse plate très limitée.

La troisième catégorie ne rassemble que des pièces incomplètes (fig. $7, \mathrm{n}^{\text {os }} 3,4$ et 5 ). Il s'agit de pointes, vraisemblablement triangulaires, à base rectiligne. La retouche est directe abrupte exclusivement. L'angulation entre les deux troncatures est de l'ordre de 60 à 70 degrés. Malgré leur caractère incomplet, il est tentant de comparer ces fragments au triangle entier découvert à une trentaine de mètres du locus (cf. $\$$ « Le mobilier dispersé »). Il s'agit d'un grand triangle, dont les troncatures sont réalisées par retouche directe abrupte (fig. $7, \mathrm{n}^{\circ} 6$ ). Une retouche inverse plate est présente à la rencontre des deux troncatures, qui présente une angulation de l'ordre de 55 degrés. Cette pièce s'apparente à un triangle de Chateauneuf (Rozoy, 1978a, Valdeyron et al., 2013; Perrin, 2013), rencontré d'ordinaire dans le sud de la France (comme par exemple à la Baume de Montclus, c. 10, $\mathrm{Pl}, \mathrm{n}^{\text {os }} 9$ à 12 , in Rozoy, 1978b). Il est toutefois plus raisonnable de considérer sa parenté avec la pointe triangulaire entière du locus 3 (fig. $14, \mathrm{n}^{\circ} 12$ ), qui ne présente plus qu'une très lointaine parenté avec le grand triangle de Châteauneuf.

Une pièce retouchée pourrait être rattachée à la catégorie des armatures triangulaires (à tranchant transversal ?) (fig. 7 , $\mathrm{n}^{\circ} 5$ ). La retouche est semi-abrupte directe à tendance envahissante et inverse plate. La pièce est toutefois trop épaisse et pourrait à la rigueur être une ébauche ou un raté, la retouche étant engagée sur un support inadéquat. Il est difficile de juger alors de son identité typologique. Sans exclure la possibilité d'essai de réalisation d'une armature tranchante de type « armature du Chatelet », nous accordons assez peu de foi à cette hypothèse.

Enfin, un support lamellaire en grès présente une retouche abrupte des bords qui en fait une probable base d'armature fracturée. D'autres fragments inidentifiables présentent des vestiges de retouche abrupte qui suggèrent qu'il s'agit de fragments d'armatures; ils n'ont pas fait l'objet d'une représentation graphique. Les difficultés de lecture de la retouche, sur le silex mais surtout sur le grès, ont fait mettre à l'écart des pièces dont l'attribution à la catégorie des armatures était trop hypothétique.

\section{Discussion sur le mobilier}

Les déchets de taille retrouvés dans le locus 1 sont très majoritairement dominés par les éclats courts et épais auxquels il faut ajouter les cassons et les éclats d'initialisation des blocs. La production lamino-lamellaire n'entre qu'à hauteur de $7 \%$ de la série (esquilles exclues). Par comparaison avec d'autres séries locales, comme Falaise (Dietsch, 1995) ou Saint-Ellier-les-Bois (Artur, 2007), la différence est très importante. Cette carence notée à partir des déchets de taille récoltés doit toutefois être nuancée par la présence plus importante de nucléus à lamelle que de nucléus à éclat (24 pièces contre 18). Le déficit du débitage lamellaire ne doit donc pas uniquement être considéré comme une absence de production lamellaire en début de chaine opératoire mais comme une absence en fin de chaine opératoire. Entre l'époque de la taille et celle de la fouille, plusieurs raisons peuvent être évoquées pour expliquer la perte des produits lamellaires : une surexploitation des supports réguliers due à la médiocrité de la matière première (prélèvement et déplacement) ou des phénomènes taphonomiques (fouille 
d'un lambeau de couche archéologique). Le tamisage partiel (humide ou à sec) n'a pas livré plus de produits lamellaires que la fouille manuelle.

Le pourcentage réduit de pièces ayant subi l'action du feu $(7 \%)$ est inférieure à celle habituellement rencontré sur les sites régionaux (pour exemple $14 \%$ à Falaise; Dietsch, 1995), mais témoignerait d'une occupation de type domestique.

La présence des micro-nucléus pose un problème récurrent dans l'étude des séries lithiques mésolithiques (Valentin, communication orale Paris, 2010). Dans l'état actuel de la recherche, ces pièces, caractéristiques du Mésolithique dans son ensemble, ne trouvent pas de justification unanime. Il est difficile de savoir si les petites esquilles prélevées ont pu avoir un rôle ou de déterminer si ce sont les nucléus en euxmêmes qui présentaient un intérêt.

L'outillage représente $9 \%$ des artefacts supérieurs à $1,5 \mathrm{~cm}$. Ce pourcentage est largement inférieur à celui enregistré sur des sites comme Falaise ou Saint-Pierre-du-Bû (respectivement 20 et $17 \%$; Dietsch, 1995), mais ne dépareraient pas sur les sites du Mésolithique moyen du NordCotentin comme Auderville " Roc de Gîte » ou Flamanville "EDF » (Ghesquière et al., 2000). La question des supports à coche se pose ici. Il est possible que certaines soient des substituts aux lames à coche multiples (lames Montbani), du fait de la carence en supports allongés.

\section{Comparaisons et attribution chrono-culturelle}

Les armatures restent très peu nombreuses dans la série, dans un pourcentage équivalent à celui du Mésolithique final de Falaise (Dietsch, 1995). Ce faible nombre empêche d'en faire une étude statistique. Deux tendances peuvent sans doute en être extraites. La première correspond à des pointes triangulaires, hélas toutes fragmentaires, dont une seule possède une retouche inverse rasante. Si l'on trouve une pièce très semblable sur le locus 3 , les comparaisons extrarégionales ne sont pas nombreuses. Elles doivent rejoindre la catégorie des pointes courtes de la fin du Mésolithique récurrentes dans la région Centre, même si elles y sont toutes issues de contextes de surface (Dufour et Leconte, 1995). Il est possible qu'elles s'inspirent de formes triangulaires larges, comme le triangle de Châteauneuf (fig. $7, n^{\circ}$ 6). La diffusion de ces pièces de tradition castelnovienne (région PACA) est bien repérée dans la vallée du Rhône où elles marquent probablement le début du Mésolithique final. Sur la façade atlantique, le mouvement de diffusion des armatures de tradition méridionale se fait davantage avec les trapèzes du Martinet/trapèzes du Payré, du groupe de GazelCuzoul (Languedoc), mais l'introduction du Castelnovien dans le groupe de Gazel-Cuzoul (vers -5500?, Valdeyron et al., 2013; Perrin, 2013) limite les interprétations. De toute évidence, les armatures triangulaires larges à base retiligne, "à épine ", trahissent une influence du sud, au moins de la Loire (Saint-Gildas 1C, L'Autruère, Marchand, 1999a et b). Les deux pointes à troncatures gibbeuses trouvent des points de comparaison avec plusieurs autres sous-types régionaux : pointes de Falaise (Ghesquière, 2012), pointes de Sonchamp, armatures à éperon, qui semblent chacune dominer un paysage régional entre la Seine et la Loire. Les deux exemplaires du locus 1 (fig. $7, \mathrm{n}^{\text {os }} 1$ et 2 ), avec la pièce du locus 3 (fig. $14, n^{\text {os }} 1$ et 3 ) sont des pièces trapézoïdales larges. Le façonnage par micro-burin est probable pour la pièce entière du locus 3 et impossible à déterminer pour la pièce fragmentée en silex du locus 1. La seconde pointe est en grès, matériau pour lequel il est difficile de considérer dans le cas de Coulmer que la fracture par micro-burin soit utilisable. Enfin, le petit triangle scalène à retouche inverse rasante discrète nous suggère la perduration des petits scalènes dans les assemblages tardifs. Devant la multiplication des sous-types régionaux (des pointes à troncatures gibbeuses en particulier, mais également des pointes d'influence méridionale), il est difficile de rattacher la série de Coulmer à un environnement chrono-culturel précis. En effet, s'il semble sensé de proposer une attribution au Mésolithique final (rien que par la présence de retouche inverse plate), les observations sur les rares séries homogènes trahissent une accélération de l'évolution des assemblages durant les quelques siècles précédant la néolithisation (Marchand, 1999a et b et 2000). Il semble que l'on puisse proposer de placer la série de Coulmer après celle de la pointe Saint-Gildas 1C (-58305480 BC; Marchand, 1999a) qui présente des triangles mais pas d'armatures à éperon et celle de la Gilardière (-56005200 BC; Marchand, 1999a) où les armatures du Chatelet sont bien présentes. La série interviendrait alors dans la première moitié du Mésolithique final, entre -5600 et -5400 .

Les lames à coches multiples constituent un des outils représentatifs du Mésolithique récent/final dans la moitié nord de la France (Rozoy, 1978b). On remarque toutefois que sur les sites du Mésolithique final régional (Falaise et Biéville-Beuville en particulier), elles sont peu typiques et rentrent assez mal dans la catégorie définie par Rozoy. À Coulmer, aucun support à coche ne peut rentrer dans cette catégorie; les coches sont toutes uniques et réalisées sur des petits supports. On peut émettre l'hypothèse que l'absence de grands supports a pu faire jouer aux éclats le rôle de substitut aux lames à coches multiples.

Les grattoirs unguiformes rappellent par leur nombre la série du Becquet à Fermanville (Ghesquière, 2012). Ils sont assez récurrents au Mésolithique mais n'apparaissent pas dans le Mésolithique final de Falaise et Saint-Pierre-du-Bû, où l'outillage est en général massif. La série de Biéville- 
Beuville en revanche, présente un nombre de petits grattoirs important (Artur, 2006), sans que l'on puisse attester avec certitude de leur appartenance au Mésolithique final en raison des conditions de découverte de la série.

Les autres types d'outils sont soit peu démonstratifs (divers éclats retouchés), soit représentés par une seule pièce. L'éclat tronqué/couteau à dos présente ainsi une retouche soignée et le choix d'un support d'un module peu fréquent dans la série. Il est toutefois assez atypique par rapport à ce que l'on connait des types régionaux (Falaise, Biéville-Beuville).

À l'exception du burin sur lame régulière et de deux pointes de flèche, on note l'absence d'artefacts caractéristiques du Néolithique en général (tranchets bitronqués, armatures tranchantes...) et du Néolithique ancien en particulier (armatures rubanés ou VSG, armatures de faucille, lames obtenues par ercussion indirecte, burins sur lame). Il semble donc que l'on puisse conclure à l'homogénéité de l'ensemble de la série. Les quelques exceptions sont soit des pièces perdues à la chasse (pointe de flèche à pédoncule et une pierre à fusil), soit le burin sur lame. Au vu de l'ensemble des caractéristiques de la série, on s'oriente vers l'hypothèse d'une attribution au Mésolithique final, caractérisé en particulier par les armatures à troncatures gibbeuses et retouche inverse plate, sans pouvoir être plus précis car des marqueurs typologiques comme les triangles à épine (" de Chateauneuf »?) ne sont pas encore suffisamment identifiés au niveau interrégional.

\section{LE LOCUS 2}

Le mobilier lithique se réduit à 280 artefacts lithiques, soit 193 déchets de taille supérieurs à $1 \mathrm{~cm}, 86$ esquilles et un fragment de percuteur en silex. Les artefacts en grès représentent $26 \%$ de la série. L'outillage est représenté par 28 pièces issues de la fouille et 3 pièces issues du diagnostic.

\section{Introduction}

Le locus 2 a été mis en évidence dans la zone ouest de la fouille. Il correspond en particulier à l'extrémité de la tranchée 22 du diagnostic, élargie sur la concentration (Ghesquière, 2009). La zone avait livré au diagnostic, outre des artefacts en silex et en grès caractéristiques de l'ensemble de la série, un nucléus lamellaire en silex bathonien et un fragment de bracelet de schiste. La possibilité d'un mésolithique tardif avait alors été proposée à titre d'hypothèse.

\section{Position stratigraphique des vestiges}

Le mobilier issu de ce locus occupe la même position stratigraphique que celui du locus 1 . Il est inclus dans la couche de transition entre les limons superficiels et les limons orangés stériles, dans une couche bioturbée non atteinte par les travaux agricoles. Il s'agit donc probablement encore une fois d'un reliquat de sol d'occupation entraîné en profondeur par les agents naturels. Le caractère domestique de cette occupation peut être discuté, au regard de la relative concentration de vestiges et du nombre assez restreint de pièces ayant subi l'action du feu.

\section{Matières premières}

La plupart des artefacts est taillé dans le silex du Pays d'Auge (74\% de la série). Un nucléus lamellaire (fig. 7bis) est en silex bathonien à grain fin. Son origine est à rechercher vers la plaine sédimentaire, à partir d'une trentaine de kilomètres de Coulmer, vers Écouché où l'on est assuré qu'au Mésolithique final, les populations avaient accès à un silex bathonien "abondant " et de bonne qualité. Le reste du mobilier est représenté par des grès à ciment siliceux. La partition des matériaux entre silex et grès est de l'ordre trois quart-un quart, comme il a été constaté pour le locus 1 , premier élément de cohérence entre les deux locus.

\section{Débitage (fig. 8)}

La production est nettement dominée par la production d'éclats (62 pièces). Ces derniers sont très majoritairement courts et épais, du fait de la qualité de la matière première (31 cassons). Ils présentent un talon épais et un bulbe légèrement triangulaire. Ces stigmates sont généralement associés à la percussion directe dure. Les nucléus liés à ce type de production sont au nombre de 29. Ils sont unipolaires ou plus souvent globuleux à multiples plans de frappe. Les enlèvements s'enchaînent jusqu'au rebroussé ou fracture, sur un plan de clivage de la roche, entraînant soit la recherche d'un nouveau plan de frappe, soit l'abandon du bloc.

La production de supports allongés n'est représentée que par $9 \%$ des vestiges, soit un fragment de lamelle, cinq éclats laminaires, un flanc de nucléus, quatre nucléus unipolaires, un nucléus pyramidal et cinq nucléus croisés. Les nucléus à lamelles offrent comme l'ensemble du mobilier des possibilités de débitage réduites. Les négatifs témoignent de l'enlèvement de produits lamellaires courts et fréquemment rebroussés. Un seul nucléus présente un débitage soigné; c'est celui en silex bathonien fin (fig. 7 bis). Les négatifs de lamelles à sa surface témoignent de la production de produits moyennement réguliers avec quelques rebroussés. Les rares stigmates de débitage observés sur les produits lamino-lamellaires et sur les nucléus suggèrent une percussion directe au percuteur de pierre. La percussion tangentielle est privilégiée ici. L'usage de galets allongés en pierre tendre (schiste par exemple, comme à Argentan; Leroy, 1991) est envisageable, mais aucune pièce de ce type n’a été retrouvée sur le site. 


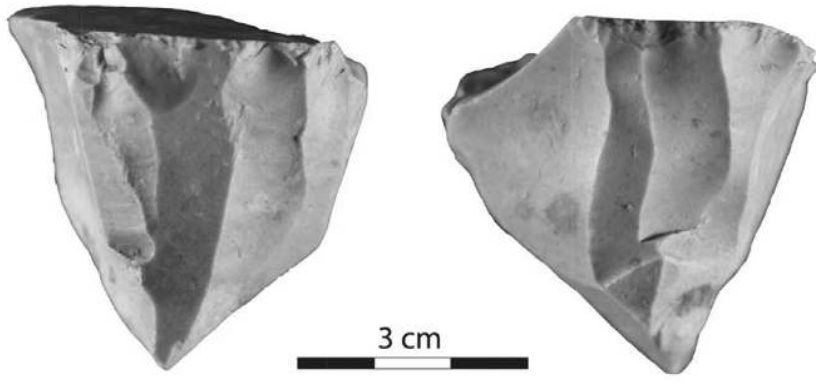

Figure 7bis : Coulmer «Beaumont ZH 16 »- Nucléus à lamelles en silex bathonien fin.

Figure 7bis: Coulmer "Beaumont ZH 16"-Bladelets nucleus (bathonien flint).

La présence de micro-nucléus (10 pièces), permettant la "production » de supports de moins de $1,5 \mathrm{~cm}$ de longueur, est notable et renvoie aux différentes questions entourant ce type de pièces évoquées pour celles du locus 1 .

\section{Outillage}

L'outillage se limite à 31 pièces, soit $16 \%$ de l'assemblage (esquilles excluses). Comme pour le premier locus, l'assemblage est dominé par les éclats retouchés (12 pièces), qui portent une retouche assez profonde qui semble résulter d'une action volontaire préalablement à leur usage. La catégorie des grattoirs est représentée par quatre pièces simples, sur éclat (fig. 9, no 3 ), un grattoir épais denticulé et quatre unguiformes (un fracturé longitudinalement). Quatre supports à coche sont présents (fig. $9, \mathrm{n}^{\text {os }} 1$ et 2 ); l'un d'entre eux réalisé sur éclat laminaire présente des coches multiples très peu profondes. Les outils sur support lamino-lamellaires vrais sont totalement absents; le fragment d'armature semble davantage être réalisé sur éclat mince ou esquille. Un gros support présente une retouche directe et inverse couvrante irrégulière. Il est fragmenté aux deux extrémités et largement plus large qu'épais. Il pourrait s'agir d'un outil prismatique très dégradé. Enfin, la base d'un possible foret pourrait représenter l'outillage perforant (fig. 9, no 4).

Parmi les outils particuliers figure un outil ovalaire découvert lors du diagnostic du locus 2. Les bords ont été entièrement repris par une retouche directe et inverse plate. Une des extrémités a ensuite été utilisée pour un usage en percussion (retouchoir, briquet?).

Plus étonnant, un fragment de bracelet de schiste a été découvert, également lors du diagnostic, dans ce qui deviendra à la fouille le centre du locus 2 , dans la même couche que l'ensemble du mobilier lithique. Sa texture et sa morphologie le rapprochent des productions de la région d'Alençon (identification N. Fromont).

\begin{tabular}{|c|c|c|c|c|c|c|c|c|c|}
\hline \multicolumn{10}{|c|}{ COULMER 2010 Locus 2} \\
\hline & \multicolumn{3}{|c|}{ silex } & \multicolumn{5}{|c|}{ grès } & \multirow[t]{2}{*}{ TOT } \\
\hline & $\mathrm{S}$ & $\mathrm{C}$ & $\mathrm{B}$ & $\mathrm{BC}$ & $\mathrm{S}$ & $\mathrm{C}$ & $\mathrm{B}$ & $\mathrm{BC}$ & \\
\hline éclat de décallotage & & 1 & & & & & & & 1 \\
\hline éclat d'entame & & 5 & & & & 1 & & & 6 \\
\hline éclat de sous-entame & & 4 & & & & & & & 4 \\
\hline éclat indéterminé & 6 & 5 & & 1 & 1 & & & & 13 \\
\hline \multicolumn{10}{|l|}{ éclat de façonnage mince } \\
\hline éclat de plein débitage & 26 & 20 & 2 & 1 & 13 & & & & 62 \\
\hline \multicolumn{10}{|l|}{ lame } \\
\hline \multicolumn{10}{|l|}{ fragment de lame } \\
\hline \multicolumn{10}{|l|}{ courte lame } \\
\hline \multicolumn{10}{|l|}{ lamelle } \\
\hline fragment de lamelle & & 1 & & & & & & & 1 \\
\hline \multicolumn{10}{|l|}{ éclat à enlèvement lamellaire } \\
\hline éclat laminaire & 3 & & & & 2 & & & & 5 \\
\hline \multicolumn{10}{|l|}{ pièce à crête } \\
\hline \multicolumn{10}{|l|}{ pièce d'avivage } \\
\hline flanc de nucléus & 1 & & & & & & & & 1 \\
\hline casson & 15 & 8 & & & 8 & & & & 31 \\
\hline débris brulé & & & 5 & 3 & & & & & 8 \\
\hline nucléus unipolaire & 1 & 2 & & & 1 & & & & 4 \\
\hline nucléus pyramidal & & & & & 1 & & & & 1 \\
\hline nucléus croisé & 4 & & & & 1 & & & & 5 \\
\hline nucléus à éclats & 4 & 13 & & & 12 & & & & 29 \\
\hline galet testé & & 12 & & & & & & & 12 \\
\hline \multirow{2}{*}{ micro-nucléus } & 5 & 2 & & & 3 & & & & 10 \\
\hline & & & & & & & & & \\
\hline \multicolumn{10}{|l|}{ esquille d'entame } \\
\hline \multirow[t]{2}{*}{ autre esquille } & 42 & 5 & 9 & & 30 & & & & 86 \\
\hline & & & & & & & & & \\
\hline \multirow[t]{2}{*}{ Total débitage } & 107 & 78 & 16 & 5 & 72 & 1 & & & 279 \\
\hline & & & & & & & & & \\
\hline \multicolumn{10}{|l|}{ Outillage } \\
\hline fragment d'armature? & 1 & & & & & & & & 1 \\
\hline grattoir sur éclat & 2 & 1 & 1 & & & & & & 4 \\
\hline grattoir denticulé & & 1 & & & & & & & 1 \\
\hline grattoir unguiforme & 1 & & & & & & & & 4 \\
\hline racloir & & 1 & & & & & & & 1 \\
\hline burin sur lame tronquée & & & & & & & & & \\
\hline lame à retouche part. reg. & & & & & & & & & \\
\hline éclat mince retouché & 2 & & & 1 & & & & & 3 \\
\hline éclat épais retouché & 2 & 7 & & & & & & & 9 \\
\hline éclat tronqué & & & & & & & & & \\
\hline fragment d'outil prismatique? & & & & 1 & & & & & 1 \\
\hline débris d'outils communs & & & & & & & & & \\
\hline limace & & 1 & & & & & & & 1 \\
\hline boucharde & 1 & & & & & & & & 1 \\
\hline support à coche & 2 & & & & 2 & & & & 4 \\
\hline foret & 1 & & & & & & & & 1 \\
\hline Total Outillage & 12 & 11 & 1 & 2 & 2 & & & & 28 \\
\hline percuteur ou éclat & 2 & 1 & & & & & & & 3 \\
\hline galet silex brut & & & & & & & & & \\
\hline microburin & & & & & & & & & \\
\hline S : sain, C : cortical, B & & & & & & & & & \\
\hline
\end{tabular}

Figure 8 : Coulmer « Beaumont ZH 16 »-Tableau de décompte du mobilier lithique du locus 2.

Figure 8: Coulmer "Beaumont ZH 16"-Inventory of the lithic artifacts from locus 2 .

\section{Discussion sur le mobilier}

L'ensemble de l'assemblage, limité à 279 pièces, présente plusieurs éléments de comparaison avec celui du locus 1 . Le choix très particulier des matériaux utilisés en particulier est presque identique. L'usage très majoritaire d'un silex de qualité médiocre constitue le premier élément. La faible disponibilité du silex à la période, alors qu'il est très largement 

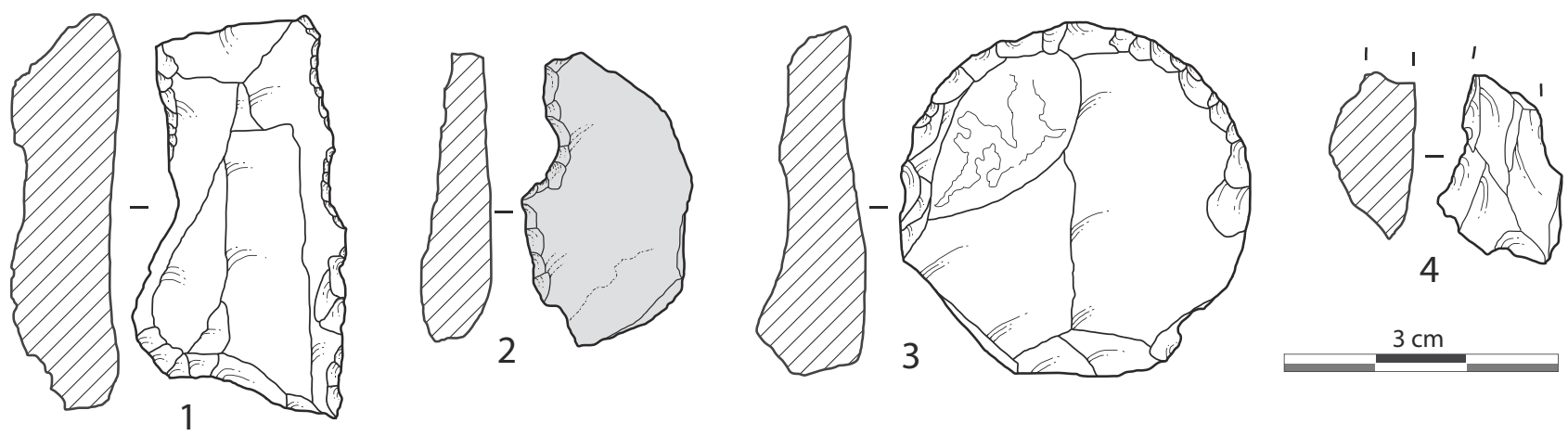

Figure 9 : Coulmer «Beaumont ZH 16 »- Locus 2 - Outillage du locus 2 - 1 : lame à coche multiples, 2 : éclat à coche, 3 : grattoir sur éclat, 4 : base de foret.

Figure 9: Coulmer "Beaumont ZH 16" - Locus 2 - Tools of the locus 2 - 1: multiple notched blade, 2: notched flake, 3: scraper on flake, 4: base drill.

présent et de meilleure qualité en sub-surface à moins de deux kilomètres, suggère un système d'approvisionnement en silex comparable pour les populations des locus 1 et 2 . L'usage du grès, de plus ou moins bonne qualité est encore une fois presque identique entre les deux locus, soit un artefact lithique sur quatre. Il semble donc qu'à la période d'occupation des deux locus, l'environnement immédiat du site soit assez comparable, avec des gisements de silex discrets, peut-être limités aux chablis. Un simple arasement des couches de surface auraient en effet permis un accès à un matériau de qualité correcte en grande quantité, non pas directement sur le site, mais à quelques kilomètres de celui-ci assurément.

Les vestiges diagnostiques relevant de la production lithique sont limités sur ce locus. Quelques éléments particuliers comme les nucléus permettent d'identifier plusieurs types de supports. Les nucléus à éclats dominent par rapport aux nucléus lamino-lamellaires. Les lames sont absentes et seul un fragment de lamelle témoigne de cette production. Il est tout à fait vraisemblable que seule une part très réduite des vestiges lithiques d'origine soit préservée, témoignant d'un débitage d'éclats courts majoritaires et, à hauteur d'un quart (?), d'une production de supports allongés. La présence de micro-nucléus n'est pas anodine et trouve son pendant dans le locus 1 , avec une représentation à hauteur d'une pièce sur vingt. Les artefacts résultant de la production de supports allongés (nucléus, produits laminaires) ne représentent qu'une part très minoritaire de l'assemblage, du même ordre également que dans le locus 1 . La présence d'un nucléus lamellaire en silex bathonien fin n'est pas discordante à une attribution au mésolithique, au contraire : la production relève du même type que celui mis en évidence sur le silex local de qualité moyenne. Seule la matière première utilisée détonne sur le site, témoignant de rapports au moins épisodiques avec les groupes humains occupant la plaine de Caen/Argentan.

L'outillage est au même titre que le reste de l'assemblage très réduit. Il témoigne d'un nombre important d'éclats retouchés et de grattoirs (dont la moitié d'unguiformes), moindres de supports à coche et d'un seul fragment d'armature. La série reste plus limitée en artefacts de petite dimension que le locus 1 (raisons taphonomiques?), ce qui a défavorisé la découverte d'éventuelles armatures. Aucun outil discordant par rapport à la période pressentie n'est présent. Les trois dominantes et le fragment d'armature renvoient à la mouvance mésolithique, assez proche de l'outillage du locus 1.

Enfin, un élément plus récent : un fragment de bracelet de schiste. Ce type de pièce est attesté au niveau régional à partir de -5100 -4800 BC, dans les cultures du Néolithique ancien, depuis le Rubané Final/VSG initial de Colombelles (Fromont, 2013; Ghesquière et Marcigny, 2000), au VSG moyen (Bostyn, 2003) et récent/à cordon et tranchet (Ghesquière et Marcigny, 2008; Fromont, 2005). Ils semblent par contre absents sur les sites du Rubané récent du Bassin parisien, comme par exemple sur le site de Démouville (Calvados, M. Le Saint-Allain, rapport en cours). Il peut évidemment s'agir d'une pièce perdue au Néolithique à l'aplomb du locus 2 et enfouie par la suite. On ne peut pas a priori exclure la possibilité pour que le locus 2 relève d'un Mésolithique tardif contemporain des premiers néolithiques installés dans la vallée de l'Orne (post $5100 \mathrm{BC}$ ?), même si cette hypothèse ne recueille pas notre adhésion. Les conclusions orientent donc davantage vers une attribution de l'ensemble au même épisode culturel que le locus 1 (et l'outillage du locus 3), soit la première partie du Mésolithique final. 


\section{LE LOCUS 3}

\section{Introduction}

Le locus 3 est inscrit dans la tranche conditionnelle de la fouille. Le diagnostic avait révélé à l'extrémité orientale de la tranchée 24 une forte concentration de mobilier interprétée comme colluvionné, avec un effet de paroi contre la limite parcellaire (fig. 2). Le locus 3, beaucoup plus dense que les deux autres, n'a pas fait l'objet du même type d'approche, que ce soit au niveau de la méthode de fouille employée (fouille fine avec ramassage par mètre carré) que de la méthode d'étude (décompte général du nombre d'artefacts en silex et en grès, des pièces brûlées et de l'outillage et décompte précis de $17 \%$ de la série, fig. 13). Au total 20558 artefacts ont été prélevés sur ce locus. Plus des trois quarts de la série sont constitués de cassons naturels. Les artefacts en grès ne sont représentés que par 273 artefacts, soit $5 \%$ de la série (hors cassons). L'outillage comprend dix-huit armatures et vingt-huit outils communs soit $1 \%$ de l'assemblage (hors cassons).

\section{Position stratigraphique des vestiges}

La stratigraphie du locus 3 est particulièrement compressée. Le substrat stérile se trouve entre 30 et $40 \mathrm{~cm}$ de la surface actuelle du sol. Le mobilier est issu des niveaux infé- rieurs de la couche de terre végétale $(5 \mathrm{~cm})$ et se prolonge dans le lambeau de limon sous jacent $(5-10 \mathrm{~cm})$. Le caractère colluvionné du mobilier, avec remaniements et transport de cassons naturels de silex avait été envisagé lors du diagnostic et semble confirmé par la fouille. La topographie en " cul-de-sac " en bas de pente de la parcelle, matérialisée par une limite parcellaire jouant le rôle de paroi, semble expliquer la présence de mobilier dans le secteur. De fait, l'hétérogénéité de cette série doit être discutée, du fait de ses différences avec les deux autres locus (les grès ne représentent que $5 \%$ des vestiges, les cassons naturels sont très présents).

\section{Répartition du mobilier}

Les artefacts ont été identifiés et fouillés sur une surface de 20 mètres de longueur et une quinzaine de largeur (fig. 11 et 12). Seule la limite nord est atteinte, avec des densités bien moindre (mais avec une moindre épaisseur de limon également) et en tout état de cause, la concentration se prolonge vers l'est, l'ouest et le sud, hors des limites de l'emprise des travaux routiers. Le caractère très désorganisé des vestiges interdit de reconnaitre une ou plusieurs concentrations, que cela soit au niveau de la totalité du mobilier ou des plans spécifiques (grès, outils, silex brûlés). Devant l'incertitude taphonomique de ce locus (colluvionnement?, reliquat de locus domestique?), il ne semble pas nécessaire de nous attarder sur les phénomènes de répartition.

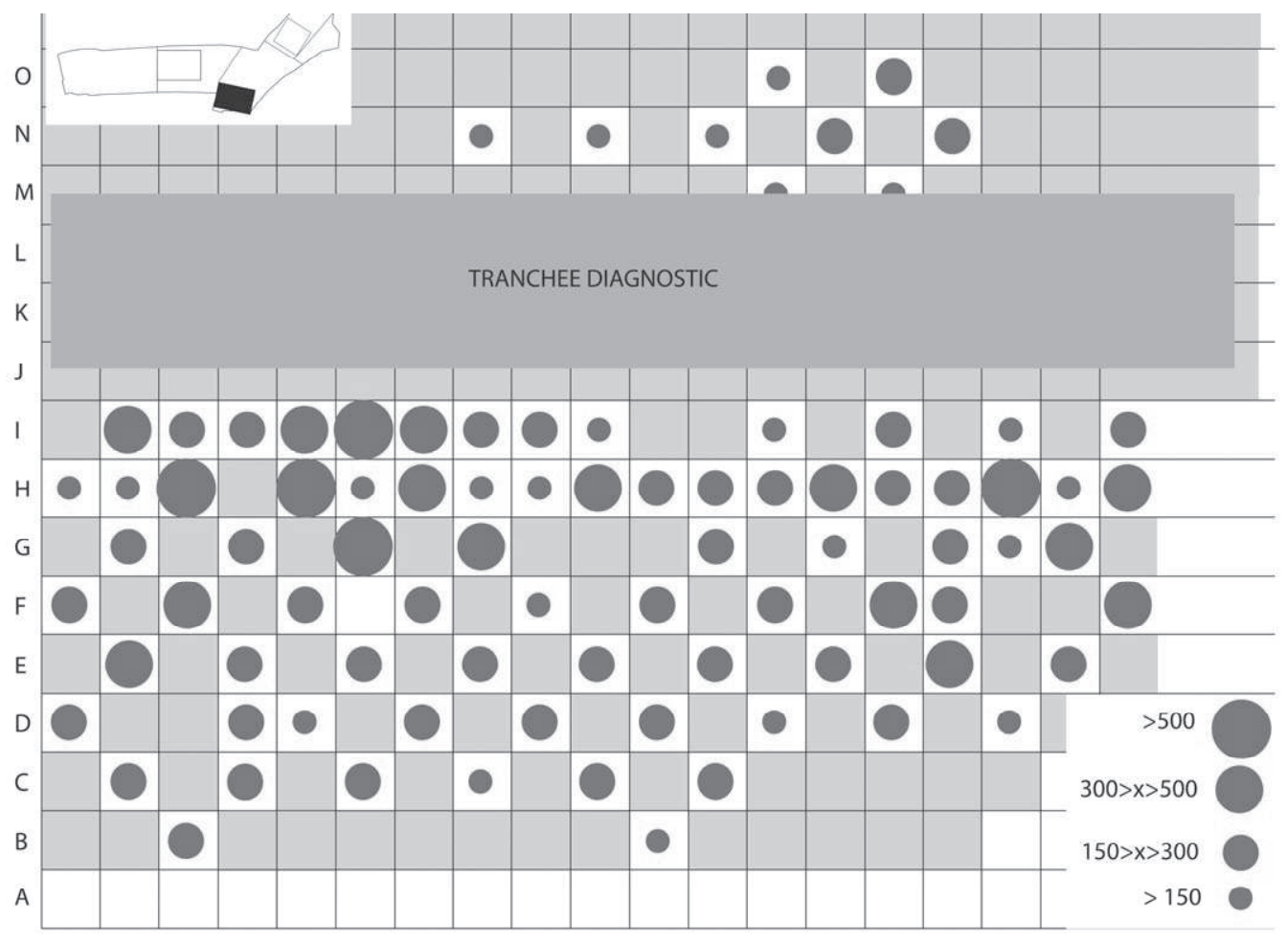

Figure 10 : Coulmer "Beaumont ZH 16 "Plan de répartition globale des artefacts du locus 3. Figure 10: Coulmer "Beaumont ZH 16"Distribution map of the artifacts of the locus 3. 
Figure 11 : Coulmer "Beaumont ZH 16"

- Plan de répartition globale des outils (étoile : armatures, point : outil commun) du locus 3.

Figure 11: Coulmer "Beaumont ZH 16"Global distribution map of the tools (star: reinforcements, dot: common tool) of the locus 3.
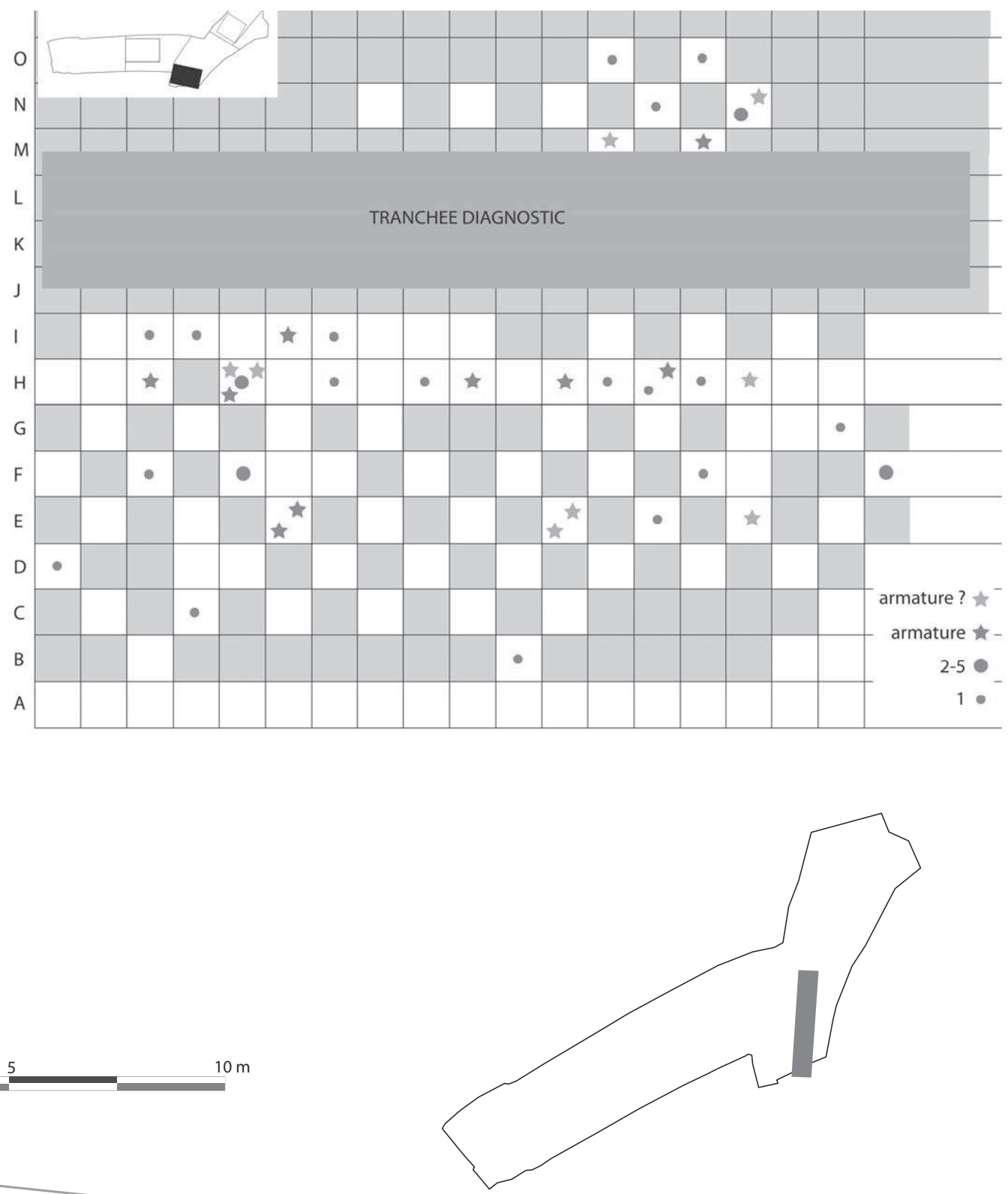

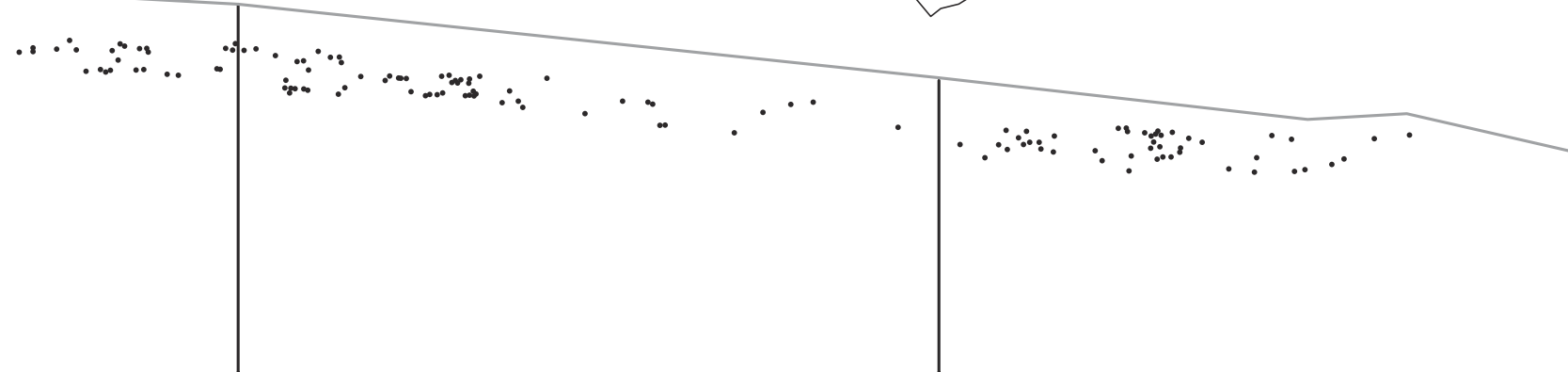

Figure 12 : Coulmer "Beaumont ZH 16 »- Répartition stratigraphique des vestiges du locus 3, à partir des quelques pièces relevées en topographie présentes dans une bande de 3 mètres de largeur, orientée nord-sud.

Figure 12: Coulmer "Beaumont ZH 16" - Stratigraphic distribution of the artifacts of the locus 3, with objects raised in topography present in a band of 3 meters in width, orientation North-South. 


\section{Le silex}

Le tri de cet important lot de 20558 pièces n’a pas été réalisé dans les mêmes conditions que pour les locus 1 et 2 . Le choix a été fait, dans le cadre du temps d'étude complémentaire imparti, de traiter un échantillon représentatif de $17 \%$ de la série (aléatoire en fonction du temps imparti), soit 3525 pièces correspondant à 21 mètres carrés répartis au hasard sur la surface de la fouille (fig. 13). Elle a permis d'estimer la quantité de cassons naturels présents sur le locus. L'étude de la production portera plus précisément sur cet échantillon, tandis que l'étude de l'outillage portera sur l'ensemble du locus, dans la mesure où il était déjà trié lors de la phase de post-fouille. Un tri précis de l'ensemble des 20558 pièces auraient néanmoins pu permettre la reconnaissance de fragments d'armatures supplémentaires. Les périodes postérieures semblent absentes ou non significatives (un fragment de hache polie en surface, quelques éclats en silex crétacé).

\section{Matières premières}

Plusieurs matières premières distinctes ont été mises en évidence sur le locus 3. Le silex du Pays d'Auge est très largement dominant avec plus de 98,5\% des vestiges, souvent sous forme de cassons naturels, ou sous forme d'éclats ou de cassons de débitage. Le grès n'est présent qu'à hauteur de $5 \%$ (273 artefacts). Quelques très rares éclats sont réalisés en silex crétacé noir translucide, dont la provenance la plus proche est la vallée de la Seine ou ses affluents, à une soixantaine de kilomètres au nord-est du site. L'absence de ce silex dans les deux autres locus peut toutefois signifier qu'il s'agit de pièces plus récentes; ce silex est régulièrement utilisé par les populations néolithiques, de par ses qualités de débitage supérieures et son affluence dans la vallée de la Seine et sur le littoral du Calvados.

\section{Débitage}

La production est très semblable à celle mise en évidence sur les locus 1 et 2 . Elle est orientée pour moitié vers la production d'éclats courts et larges. Les lames et lamelles sont faiblement représentées $(8 \%)$. En tenant compte de la matière première de qualité médiocre, on peut adjoindre les éclats laminaires à cette production; l'ensemble des vestiges relatifs à une production identifiée de supports allongés (lames, lamelles, éclats laminaires, nucléus) s'élève à 20,5\% de la série, esquilles non comprises. Comme dans le locus 1 , les micro-nucléus sont très fréquents ( $9 \%$ de la série), ce dont témoigne également un nombre d'esquilles très important ( 2 pièces sur 3 , cassons naturels exclus). Les supports lamino-lamellaires réguliers (de style Montbani) sont anecdotiques et ont fait l'objet d'une utilisation comme supports d'armatures (fig. $14, \mathrm{n}^{\text {os }} 5,6$ et 12 ).

\section{Outillage}

Sur les 46 outils mis en évidence, trois catégories dominent nettement, les armatures, les grattoirs et les éclats retouchés et/ou denticulés. Les supports à coche ne constituent pas ici une catégorie dominante, bien qu'ils soient bien présents (4 pièces).

Les grattoirs sont représentés par 12 pièces, six de type simples sur éclat, réalisés sur des supports calibrés en 35 et $50 \mathrm{~mm}$ de longueur, sur des pièces courtes ou allongées. La retouche concerne exclusivement l'extrémité distale; elle est semi-abrupte et détermine un front plus ou moins convexe (fig. 14, no 23 et 24). Les autres grattoirs sont des petites et très petites pièces, qui peuvent être classées parmi les unguiformes (fig. 14, $\mathrm{n}^{\text {os }} 14,15$ et 20 ). La retouche concerne ici aussi uniquement l'extrémité distale.

Les éclats retouchés et denticulés comprennent 9 pièces. Ils offrent peu de différentiation entre retouche et denticulation au niveau de la retouche, avec simplement des nuances dans la régularité. Les fronts sont toujours assez courts et peuvent résulter pour nombre d'entre eux uniquement de l'usage des pièces (outils a posteriori). Une seule exception est présente avec une grande pièce tabulaire naturelle, qui a fait l'objet de tentatives de débitage et qui présente une retouche denticulée de tout un bord.

Les supports à coche, bien que proportionnellement moins nombreux que dans le locus 1 , sont tout à fait comparables morphologiquement. Ils sont en général courts et peu épais (fig. 14, ${ }^{\circ} 16$ ). Une pièce allongée (fragment de lame ou éclat laminaire) présente deux coches jumelles qui l'installent un peu plus que les autres dans la catégorie des lames Montbani (fig. 14, $\mathrm{n}^{\circ} 18$ ).

Le reste de l'outillage commun est constitué par deux lames retouchées; les supports, bien que peu réguliers, présentent les marques d'un débitage assez régulier, que l'on pourrait qualifier de Montbani ainsi qu'un racloir (fig. 14, $\left.\mathrm{n}^{\circ} 19\right)$.

\section{Les armatures}

Douze armatures ont été identifiées de façon certaine. Six autres très fragmentaires et/ou peu lisibles ont été rattachées de façon plausible mais non certaine à la catégorie des armatures. Ces chiffres sont à rapporter à la masse de vestiges lithiques dans ce corpus (20 500 artefacts, cassons naturels à $75 \%$ et esquilles à $17 \%$ ). Sur les douze armatures incontestables, trois sont cassées et ne peuvent être rattachées à une catégorie en particulier. Il s'agit vraisemblablement de bases pour deux d'entre elles (fig. 14, ${ }^{\text {os }} 6$ et 9), de bases de pointes et, pour le dernier, d'un fragment mésial d'armature (fig. 14, $\mathrm{n}^{\circ} 10$ ). 


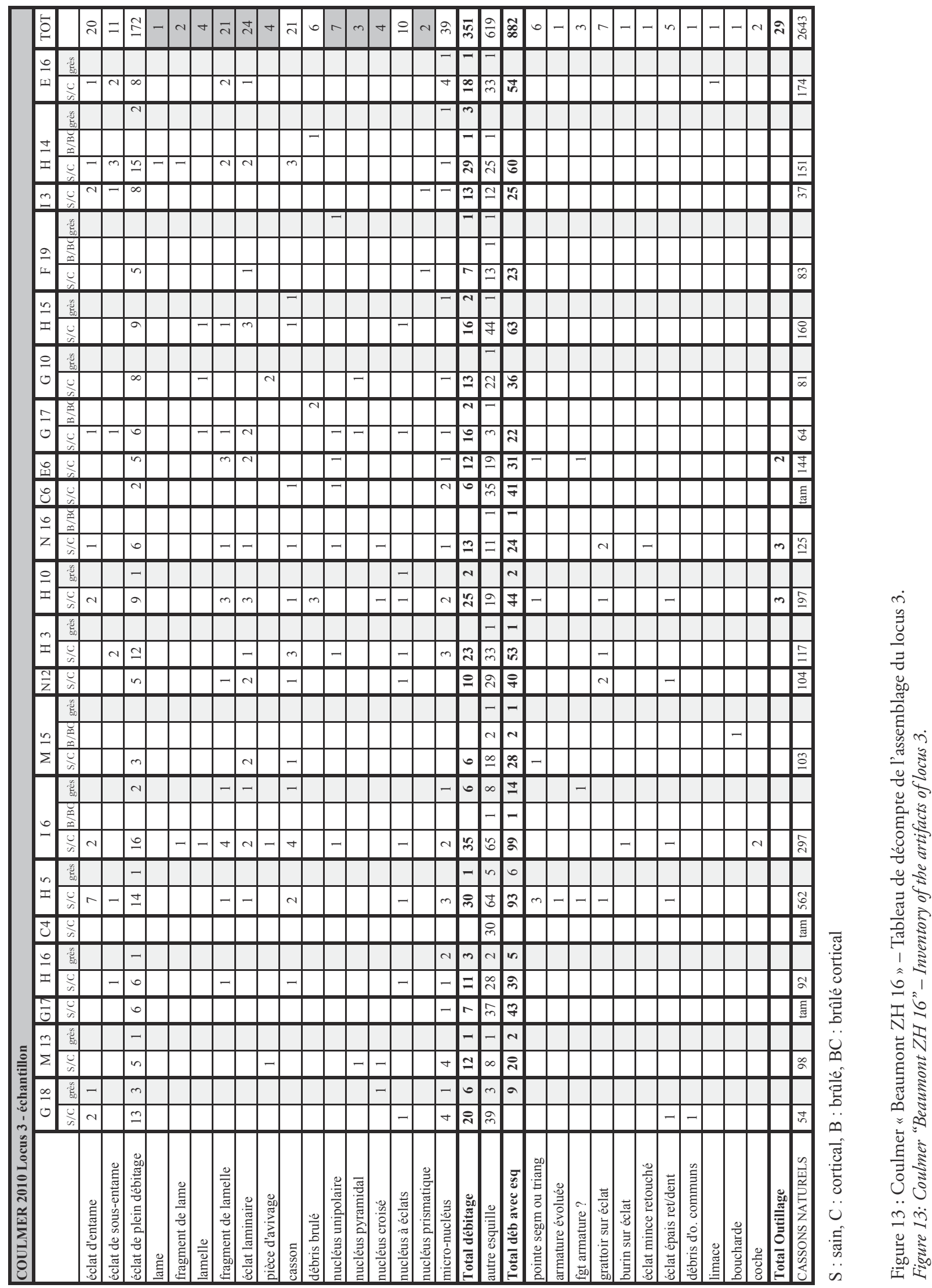



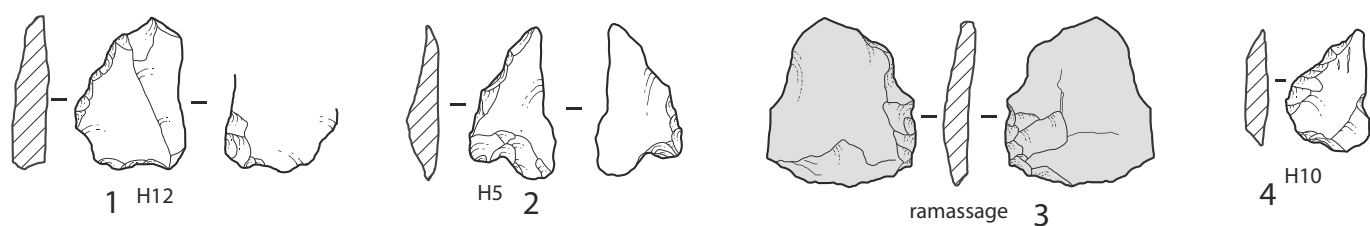

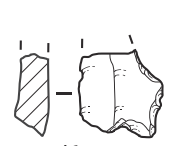

$5^{16}$

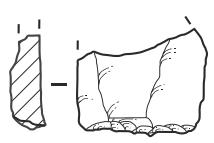

H14 6
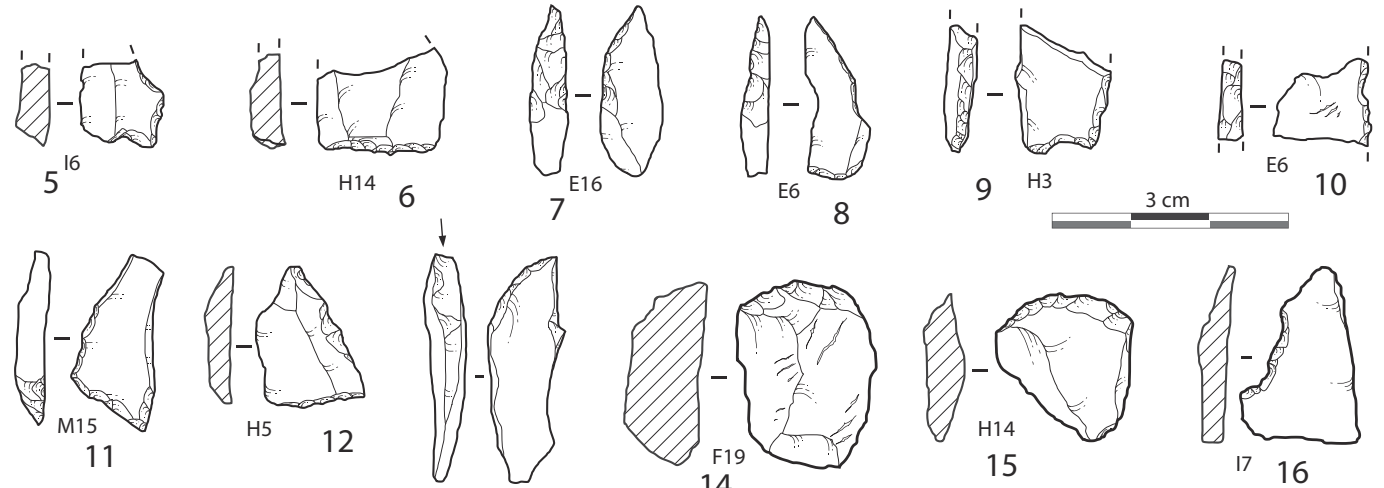

ramassage 13

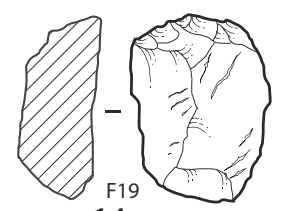

14

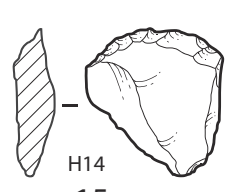

15
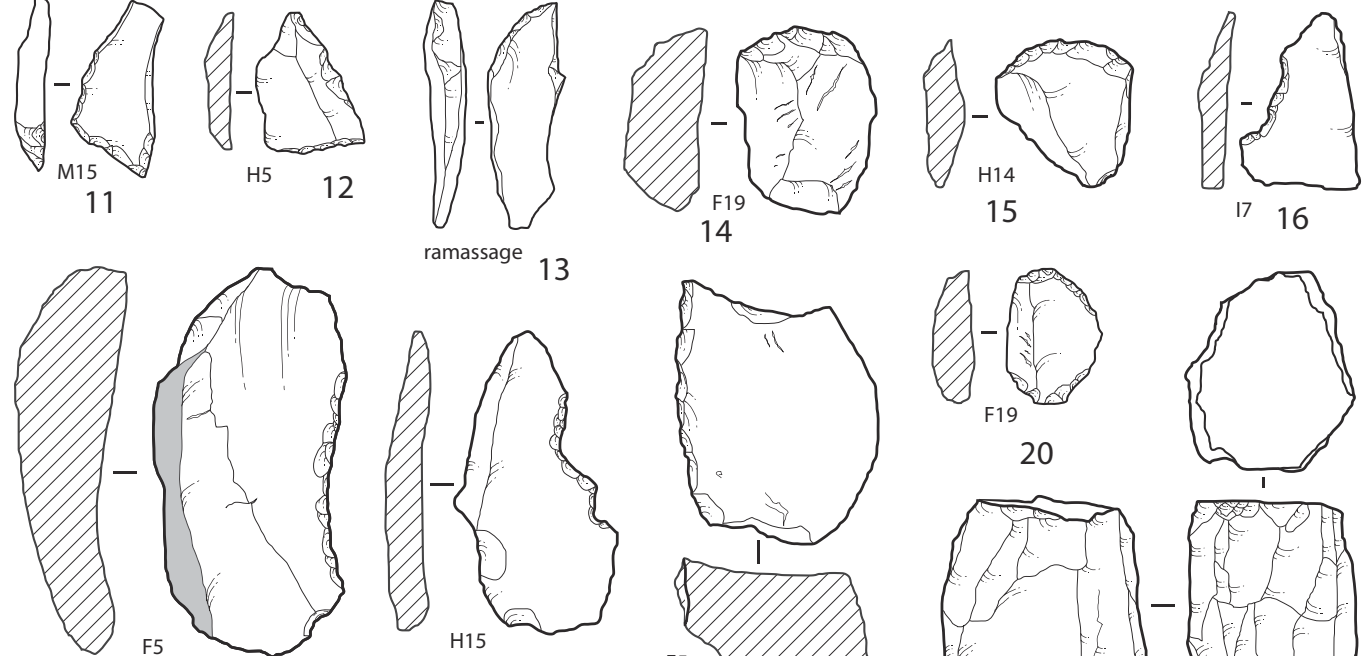

17
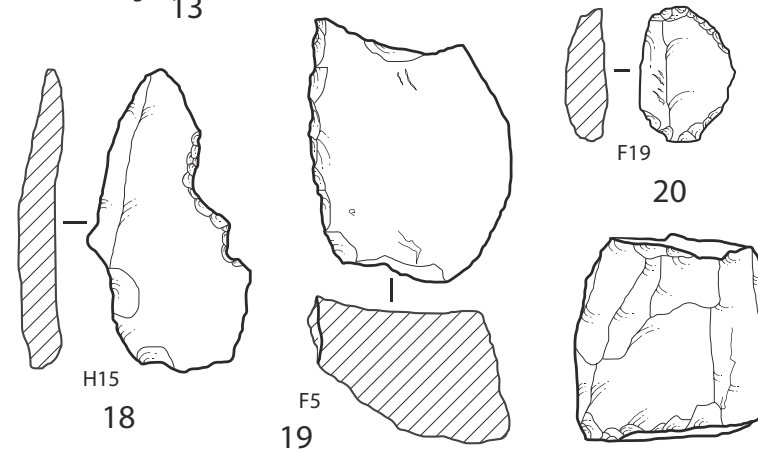

20
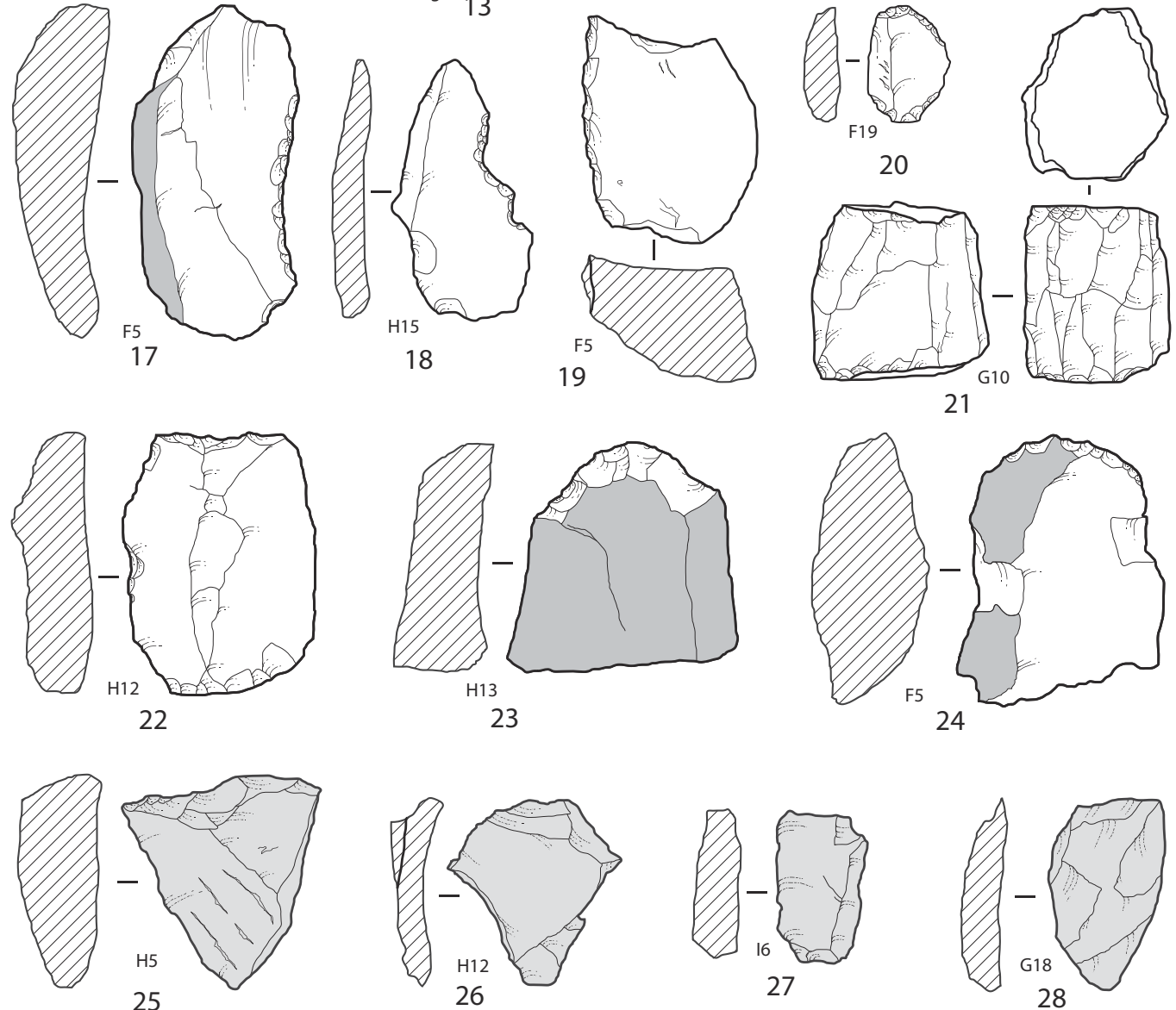

Figure 14 : Coulmer « Beaumont ZH 16 " - Outillage du Locus 3 - 1 à 4 : pointes à troncatures gibbeuses, 5, 6, 9, 10 : armatures fragmentées (pointes?), 7, $8:$ pointes segmentiformes, $11:$ scalène, 12 : pointe triangulaire, $13:$ burin, 14, 15, $20:$ grattoirs unguiformes, 16, 18 : supports à coche, 17 : éclat retouché, 19 : racloir, 21 : nucléus prismatique, 22 : troncature ou grattoir?, 23 et 24 : grattoirs simples sur éclat, 25 : éclat retouché, 26 à 28 : éclats bruts (en blanc : silex, en grisé : grès).

Figure 14: Coulmer "Beaumont ZH 16" - Tools from Locus 3 - 1 to 4: points with gibbous truncations, 5, 6, 9, 10: fragmented arrow heads (points?), 7, 8: segmentiform points, 11: scalene, 12: triangular point, 13: burin, 14, 15, 20: unguiform scrapers, 16, 18: notched blanks, 17: improved flake, 19: scraper, 21: prismatic nucleus, 22: truncated flake or scraper, 23 to 24: simple scrapers on flakes, 25: improved flake, 26 to 28: rough flakes (in white: flint, in gray: sandstone). 
Trois pointes à troncatures gibbeuses sont présentes. La première, assez large et s'apparentant à un trapèze, présente une retouche semi abrupte directe et une retouche inverse rasante limitée (fig. 14, $\mathrm{n}^{\circ} 1$ ) sur une base très légèrement concave. Sa morphologie est comparable à celle des deux pointes à troncature gibbeuse du locus 1 (fig. $7, \mathrm{n}^{\text {os }} 1$ et 2 ), même si son module est plus réduit. La seconde pointe à troncature gibbeuse constitue un type un peu différent. Elle est étroite et sa base est franchement concave (fig. 14, $\mathrm{n}^{\circ} 2$ ), dans une morphologie qui est à égale distance des armatures à éperon et des pointes de Sonchamp (Marchand, 1999a et b; Girard, 1995). La troisième est réalisée en grès. Sa base est laissée brute et sa troncature alterne retouche directe abrupte et semi-abrupte directe et inverse.

Un triangle scalène assez régulier et de module moyen (fig. 14, $\mathrm{n}^{\circ} 11$ ) présente une retouche directe abrupte exclusive.

Deux pointes triangulaires ont une base rectiligne très faiblement oblique et une angulation entre les deux troncatures peu aigue ( 65 degrés et 75 degrés; fig. $14, n^{\text {os }} 4$ et 5 ). Elles présentent de nombreux points communs avec les trois fragments de pointes triangulaires du locus 1. Langulation de moins en moins aigüe des deux troncatures par rapport aux pièces du locus 1 les apparente toutefois à certaines formes atypiques de pointes de Sébouville (fig. $7, \mathrm{n}^{\mathrm{os}} 6,8$, 9 et 15 par exemple; Girard, 1995). La troisième pointe triangulaire entière (fig. $14, \mathrm{n}^{\circ} 12$ ) est proche des pointes typiques de la culture B-VSG moyen à décor imprimé, avec lesquelles elle partage le caractère légèrement décalé de la petite base comme par exemple à Poses (Bostyn, 2003), tout en existant par ailleurs au niveau local en contexte mésolithique, à Fermanville, Cosqueville ou Saint-Ellier-les-Bois par exemple (Ghesquière, 2012).

Deux pointes à dos courbe, étroites, complètent le corpus (fig. $14, \mathrm{n}^{\text {os }} 7$ et 8 ). Il s'agit de segments de cercle, réalisées à partir de supports lamellaires courts et épais, par une retouche directe abrupte. Leur robustesse les identifie davantage à une fonction d'extrémité apicale plutôt que d'élément de barbelure.

Enfin, une armature fragmentée correspond éventuellement à la base d'un trapèze (rectangle?) (fig. 14, nº 6 ) .

\section{Comparaison et attribution chrono-culturelle}

Les meilleurs éléments de comparaison de l'outillage sont avec celui du locus 1 . Les quatre dominantes : armatures, grattoirs, éclats retouchés/denticulés et dans une moindre mesure les supports à coche, attestent une proximité chronoculturelle. Le pourcentage d'unguiformes est toujours important et renvoie, au niveau régional, aux contextes du Nord-Cotentin (sites de Fermanville, Ghesquière, 2012) et sont aussi bien représentés dans le Gildasien ou le Retzien (Marchand, 1999a et b) en tenant compte d'une industrie de plus petit module à Coulmer. Les supports à coche, toujours bien représentés dans les industries du Mésolithique final dans le Grand-Ouest, sont ici atypiques. Un seul support présente deux coches jumelles, alors que ces pièces à coches multiples dominent d'ordinaire cette catégorie. Cela résulte éventuellement d'une carence en supports allongés dans la série, sans certitude. En Basse-Normandie, seules les deux industries riches en lames régulières de Falaise (Dietsch, 1995) et Biéville-Beuville (Artur, 2006 et 2007) possèdent des lames à coches multiples.

Le rapport du nombre d'armatures sur le nombre d'artefacts en grès $(6,2 \%)$ est assez proche de celui du locus 1 $(3,9 \%)$. Pour l'outillage commun, le rapport avec l'assemblage en grès reste d'ailleurs également dans des pourcentages comparables $(9,5 \%$ pour le locus 3 et $14,2 \%$ pour le locus 1). Les comparaisons nous orientent vers les complexes à pointes triangulaires/trapéziformes à troncatures gibbeuses. Dans les contextes les plus proches de Coulmer, on trouve le complexe à pointes de Falaise, le complexe à pointes de Sonchamp et le complexe à armatures à éperon. Le premier se trouve à une quarantaine de kilomètres à l'ouest, le second à 140 kilomètres à l'est et le troisième à 200 kilomètres au sud; cela pour le cœur de ces complexes mais pas pour leurs limites ou leurs marges. De fait, la proximité typologique entre ces techno-complexes témoigne peut-être de liens sociaux entre ces populations regroupées entre Seine et Loire au Mésolithique final.

La faible présence de séries homogènes limite toutefois les comparaisons avec Coulmer. Dans le complexe à pointes de Falaise, si l'on exclut les séries de Falaise et Saint-Pierredu-Bû (Dietsch, 1995), cohérentes mais composées uniquement de pointes de Falaise, on ne trouve que les séries du Nord-Cotentin à proposer une mixité de formes, hélas sans certitude quant à leur homogénéité. La même remarque peut être faite à partir de l'assemblage de Biéville-Beuville (Artur, 2006 et 2007). Les séries à pointes de Sonchamp, provenant des sables du Bassin parisien, offrent une homogénéité d'ensemble dans le meilleur des cas (Sonchamp, Sébouville, Girard, 1995; Rozoy, 1978b). Enfin, les sites de l'estuaire de la Loire livrent des corpus, apparemment homogènes, qui ont fait l'objet d'études complètes (en particulier Marchand, 1999a) qui ont permis à ce dernier de proposer un phasage du Gildasien et du Retzien sur tout ou partie de la séquence Mésolithique récent/final. Les éléments de comparaison les plus pertinents sont les séries de SaintGildas $1 \mathrm{C}$, qui propose des triangles à angulation aigüe des deux troncatures et des petits et grands éléments scalènes (5800-5500 BC) et la série de la Gilardière, qui comprend des pointes à troncatures gibbeuses (pointes à éperon), de rares éléments scalènes, des trapèzes et des armatures du chatelet (5600-5200 BC). La série de Coulmer, emprun- 
tant les triangles du Gildasien et les armatures évoluées du retzien, pourrait se situer dans une fourchette hypothétique de 5600-5300 cal BC.

L'Île-de-France et le Centre sont deux régions qui pourraient offrir des séries comparables. On pense en particulier aux séries de Sonchamp et de Sébouville (Rozoy, 1978b), qui ont livré un nombre important de pointes à troncatures gibbeuses (pointes de Sonchamp), malheureusement sans contexte d'association fiables avec le reste de l'industrie (ramassage de surface).

Enfin, la présence de petites pointes triangulaires (fig. 14, $\mathrm{n}^{\text {os }} 4$ et 12 ) témoigne d'un modèle que l'on retrouve dans le B-VSG moyen-à décor imprimé. Il est encore trop tôt pour déterminer s'il s'agit d'une convergence de formes ou d'une véritable influence. On ne peut exclure que le groupe à " pointes de Sébouville » ait influencé les armatures du B-VSG moyen, qui ont probablement joué un rôle de primo-colonisateurs dans des secteurs isolés des grandes vallées en Normandie (vers 5100-5000 cal BC?).

\section{Conclusion du locus 3}

Il est possible que le locus 3 constitue sur le site un troisième locus mésolithique. Il est également possible que la série attribuée au Mésolithique du locus 3 (env. $25 \%$ des artefacts) corresponde à du mobilier colluvionné à partir du locus 2 situé en amont. Par comparaison avec les séries de Basse-Normandie ou des Pays de la Loire, l'attribution chrono-culturelle s'oriente vers le Mésolithique final. Le caractère hétéroclite de ce locus, en position secondaire, probablement colluvionné, ne permet pas d'étendre plus avant les comparaisons. L'ensemble de l'outillage pourrait toutefois relever d'une unique occupation, typologiquement et morphologiquement proche de celle du locus 1 .

\section{LE MOBILIER DISPERSÉ}

\section{Introduction}

Un total de 422 artefacts a été découvert sur les 5 zones de dispersion des silex (la zone A, entourant le locus 1 , a été rattaché à celui-ci) (fig. 2). Parmi l'assemblage, 313 pièces sont réalisées en silex local, de qualité moyenne à médiocre. Deux éclats sont en silex crétacé et un en silex bathonien fin de la Plaine de Caen (silex dit du Cinglais). 106 artefacts sont réalisés en "grès lustré " plus ou moins fin.

\section{Position stratigraphique des vestiges}

Les vestiges ont été mis en évidence dans le même horizon que le mobilier des locus 1 et 2 , la couche de transition entre les limons superficiels et les limons orangés stériles, dans une niveau bioturbé inaccessible aux travaux agricoles. Il s'agit donc encore une fois d'un reliquat de sol entraîné en profondeur par les agents naturels.

\section{Le mobilier}

Secteur D : 15 silex, 5 grès.

Secteur $\mathrm{E}: 69$ silex, 18 grès.

Secteur $\mathrm{F}: 37$ silex, 11 grès.

Secteur $\mathrm{G}: 79$ silex, 44 grès.

Secteur $\mathrm{H}$ : 116 silex, 28 grès.
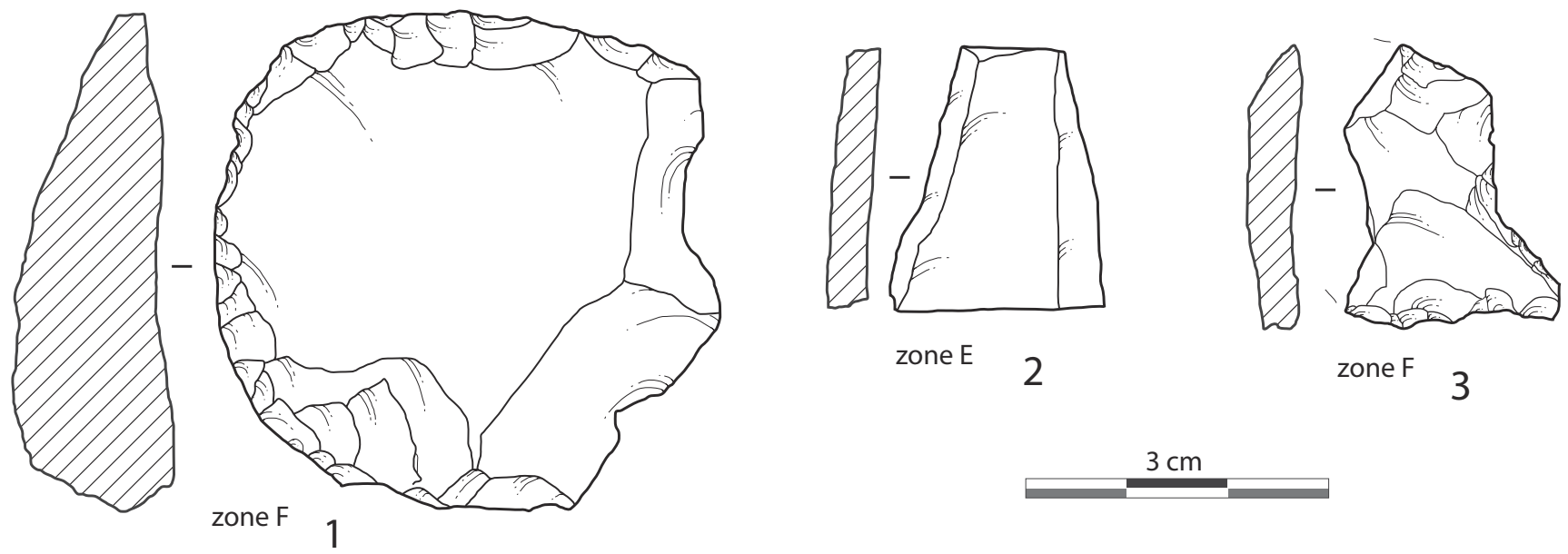

Figure 15 : Coulmer "Beaumont ZH 16 »-Outillage dispersé - 1 : grattoir, 2 : fragment de lame en silex bathonien fin (produit par percussion indirecte?), 3 : probable pointe à troncatures gibbeuses.

Figure 15: Coulmer "Beaumont ZH 16"-Dispersed tools - 1: scraper, 2: fragment of blade made from fine bathonian flint (produced by indirect percussion?), 3: probable point with gibbous truncations. 
À l'exception des zones $\mathrm{E}$ et $\mathrm{F}$, le mobilier est tout à fait comparable aux assemblages des locus 1 et 2 . Le débitage d'éclat y est nettement prédominant même si une industrie lamino-lamellaire est attestée, au moins d'après les négatifs de quelques nucléus. La découverte des pièces étant uniquement dû au décapage à la pelle mécanique, les petites pièces sont largement sous-représentées, par rapport par exemple au locus 1 . Cela a réduit d'autant les possibilités de mettre en évidence d'éventuelles armatures et deux seulement sont présentes. La première correspond typologiquement à un triangle de Châteauneuf (fig. 7, n ${ }^{\circ}$ 6), qui traduit l'influence des assemblages méridionaux. La seconde est une pointe à troncature gibbeuse fragmentaire fig. $15, \mathrm{n}^{\circ} 3$ ), assez proche des exemplaires des locus 1 et 3 . Le reste de l'outillage se limite à quatre grattoirs (fig. $15, \mathrm{n}^{\circ} 1$ ), trois éclats retouchés et deux supports à coche. On note la présence d'un fragment de lame régulière en silex bathonien fin (silex du Cinglais; fig. $15, \mathrm{n}^{\circ} 2$ ). Ce fragment ainsi que le burin sur lame du locus 1 et le fragment de bracelet de schiste du locus 2 témoignent d'une pollution probable par quelques vestiges du Néolithique ancien.

Les zones $\mathrm{E}$ et $\mathrm{F}$ sont un peu particulières, bien que le mobilier en grès y soit représenté de manière comparable à celui des autres zones (une pièce sur quatre), quelques outils particuliers (un gros grattoir sur éclat, deux gros percuteurs en silex, un fragment de hache polie en silex) suggèrent une pollution du secteur situé à l'extrême est de l'emprise par du mobilier néolithique.

\section{Conclusion sur le mobilier dispersé}

La faible, voire très faible concentration d'artefacts correspond sans doute à des secteurs de dispersion de mobilier entre les locus, éventuellement des zones d'activités à l'écart de l'habitat. Les caractéristiques des pièces, matière première, débitage et supports retouchés, semblent homogènes et comparables aux assemblages des locus 1 et 2 (voire 3 pour l'outillage). Il semble que l'on puisse rattacher l'ensemble des pièces dispersées à l'occupation du Mésolithique final. La zone orientale de l'emprise semble toutefois présenter quelques pièces néolithiques qui témoignent d'une perturbation chrono-culturelle, au moins limitée, d'une petite partie de l'emprise.

\section{ConClusion gÉNÉrale}

Le site de Coulmer, installé sur la première terrasse de la vallée de la Touques, bénéficiait d'un environnement très favorable, avec une large ouverture sur la vallée (fig. 1 et 2). Cette large vallée partiellement inondée à la mauvaise saison (actuellement au moins), offrait un vaste potentiel d'activités halieutiques. Le site offre par ailleurs un vaste panorama vers le sud.

Les témoins lithiques à l'issue de la fouille reflètent la présence de plusieurs occupations dont seuls quelques reliquats ont été retrouvés. Elles se manifestent particulièrement par une carence en matière première lithique de qualité. Malgré la faiblesse des séries (respectivement seize, une et dix-huit armatures pour chacun des trois locus), il semble que l'on puisse proposer l'idée d'une simultanéité des occupations. L'intérêt de celles-ci est indéniable. Cette période précédant directement la néolithisation souffre en effet d'un manque cruel de données homogènes entre la Loire et la Picardie, même si les séries de ramassage de surface restent relativement bien représentées. L'assemblage d'armatures repose sur deux types caractéristiques : les pointes à troncature gibbeuse et les petites pointes triangulaires. Les premières présentent une retouche inverse rasante et peuvent être comparées aux pointes de Sonchamp et éventuellement se rattacher au même super-complexe incluant les groupes situés entre Seine et Loire au Mésolithique final. Les pointes triangulaires, qui ne présentent pas de retouche inverse rasante, se partagent entre celles développant une « épine » (influence méridionale?) et celles à base légèrement oblique qui se rapprochent des pointes caractéristiques du B-VSG moyen. L'influence de ces armatures du Mésolithique final sur l'armement du B-VSG (ou le contraire?), primo-colonisateur (probables) de la Basse-Normandie non littorale constituer un axe de recherche qu'il convient de développer à l'avenir, sur des séries mieux étoffées.

\section{Bibliographie}

Artur E., 2006 - Étude du matériel lithique du site de BiévilleBeuville (Calvados) : une approche du Mésolithique final dans la plaine de Caen, Mémoire de master I, université de Rennes I, inédit, $102 \mathrm{p}$.

Artur E., 2007 - Comparaison des caractéristiques des débitages laminaires et des données typologiques des armatures sur 3 sites du Mésolithique récent/final en Basse-Normandie, Mémoire de master II, université de Rennes I, inédit, 24 p.

Bostyn F. (dir.), 2003 - Néolithique ancien en Haute-Normandie : le village Villeneuve-Saint-Germain de Poses "Sur la Mare » et les sites de la boucle du Vaudreuil, Société Préhistorique Française, Travaux 4, 2003, 343 p.

Dufour Y. et Leconte F., I 995 - " Nouvelles séries d'armatures évoluées dans le Loiret et en Loir-et-Cher ", Épipaléolithique et Mésolithique du Sénonais et des régions voisines, Actes du colloque de Passy, 20-21 novembre 1993, cahier nº 2, p. 125-132. 
Dietsch M.-F., I995 - «Les stations du Mésolithique final de Falaise et Saint-Pierre-du-Bû ", Revue archéologique de l'Ouest, suppl. $n^{\circ} 7,1995$, p. 5-21.

Fromont N., 2005 - «Les anneaux en pierre dans le Nord de la France et la Belgique au Néolithique ancien : structuration des productions et circulation des matières premières ", Unité et diversité des processus de néolithisation sur la façade atlantique ( $6^{e}-4^{e}$ millénaires av. J.-C.), in Marchand, Tresset (dir.), Table ronde de Nantes 26-27 avril 2002, Mémoire XXXVI de la Société Préhistorique Française, 2005, p. 203-212.

Fromont N., 20 I I - Anneaux et cultures du Néolithique ancien, BAR International Series 2499, 642 p.

Ghesquière E., Lefèvre P. Marcigny C. et Souffi B., 2000 - Le Mésolithique moyen du Nord-Cotentin, Basse-Normandie, France, British Archaeological Reports (BAR) International Series, Oxford, no 856, 292 p.

Ghesquière E. et Marcigny C., 2000 - «Un village rubané en Basse-Normandie? L'évaluation du site de la ZAC du Lazzaro à Colombelles (Calvados) ", Bulletin de la Société Préhistorique Française, t. 97, n³ 3, p. 405-419.

Ghesquière E. et Marcigny C., 2008 - « Le Néolithique ancien dans l'Ouest de la France ", Constructions de l'archéologie, Archéopages hors série, p. 55-59.

Ghesquière E., 2009 - Rapport de diagnostic sur le barreau Coulmer-Gacé, dépôt SRA de Basse-Normandie, 2009, 80 p., inédit.

Ghesquière E., 20 Io - "Une fosse (de stockage?) du Mésolithique récent à Ronai " La Grande Bruyère " (Orne, Basse-Normandie) ", Bulletin de la Société Préhistorique Française, 2010, vol. 107, n³, p. 595-596.

Ghesquière E., 2012 - Le Mésolithique en Basse-Normandie, Thèse de l'EHESS soutenue à Toulouse sous la direction de J. Guilaine, 758 p.

Girard P., I995 - "Le gisement mésolithique ancien d'Attray (Loiret) ", Épipaléolithique et Mésolithique du Sénonais et des régions voisines, Actes du Colloque de Passy, 20-21 novembre 1993, cahier no 2, p. 105-112.
Leroy D., I99I - "Le site mésolithique d'Arma-Maquette à Argentan, Orne ", Revue archéologique de l'Ouest, t. 8, p. 25-46, 16 fig.

Marchand G., I999a - La Néolithisation de l'Ouest de la FranceCaractérisation des industries lithiques, BAR International Series 748, 1999, $453 \mathrm{p}$.

Marchand G., I999b - «Éléments pour la définition du retzien », L'Europe des derniers chasseurs, Épipaléolithique et Mésolithique, Actes du $5^{\mathrm{e}}$ colloque international UISPP, Commission XII, Grenoble, 18-23 septembre 1995, Paris, éd. du CTHS, p. 213224.

Marchand G., 2000 - «La néolithisation de l'Ouest de la France : aires culturelles et transferts techniques dans l'industrie lithique ", Bulletin de la Société Préhistorique Française, t. $97, \mathrm{n}^{\circ} 3$, p. $377-404$.

Perrin T., 2013 - «Potentialités de contacts entre mésolithiques et néolithiques dans le sud de la France", in Transitions, Ruptures et Continuité en Préhistoire, XXVII ${ }^{\mathrm{e}}$ Congrès Préhistorique de France, Bordeaux-Les Eyzies, 31 mai-5 juin 2010, Paris, Société Préhistorique Française, p. 357-372.

Rozoy J.-G., 1978a - Typologie de l'Épipaléolithique (Mésolithique) franco-belge, Bulletin de la Société archéologique champenoise, $\mathrm{n}^{\circ}$ spécial juillet $1978,120 \mathrm{p}$.

Rozoy J.-G., I978b - Les derniers chasseurs, Bulletin de la Société archéologique champenoise, $\mathrm{n}^{\circ}$ spécial juin 1978, 3 vol., 1256 p., 259 fig.

Valdeyron N., Manen C. et Bosc-Zanardo B., 2013 "Mésolithique récent/final et néolithisation du sud-ouest de la France : vers de nouvelles perspectives? ", in Transitions, Ruptures et Continuité en Préhistoire, XXVII congrès préhistorique de France, Bordeaux-Les Eyzies, 31 mai-5 juin 2010, Paris, Société préhistorique française, p. 373 à 391.

Verjux C., 2000 - Les fosses mésolithiques d'Auneau (Eureet-Loir - France), in Méso'97, Actes de la Table-ronde "Épipaléolithique et Mésolithique ", Lausanne, 21-23 novembre 1997, P. Crotti éd., Cahiers d'archéologie romande $\mathrm{n}^{\circ} 81$, p. 129-138. 
Zusammenfassung: Die Steingeräteindustrie von drei Fundansammlungen des Endmesolithikums bei Coulmer (Orne) - Eine im Jahr 2010 durchgeführte Rettungsgrabung im Bereich einer kleinen Straßentrasse in der Nähe von Gacé (Orne, Basse-Normandie, Frankreich) hat zur Entdeckung von drei nur teilweise erhaltenen Fundstellen geführt, die ins Endmesolithikum gestellt werden können. Die taphonomischen Beobachtungen, die an dem in die anstehenden Lehme eingebetteten Fundmaterial durchgeführt werden konnten, verweisen darauf, dass bei den ersten beiden Fundansammlungen (loci 1 und 2) das Material durch natürliche Prozesse (Wurzeln, Tierbauten) in den tieferen Untergrund verfrachtet worden sein muss. Dagegen scheint die vertikale Fundverteilung bei der dritten Fundstelle, locus 3, eine Bildung der Fundansammlung durch verschiedene Erosions- und Ablagerungsvorgänge im Bereich einer wenig deutlich ausgeprägten Plateaukante anzuzeigen. Aus diesem Grund finden sich in der Fundserie einzelne störende Elemente (einige moderne Fundobjekte, zwei Pfeilspitzen, ein Armreif aus Lignit, ein Fragment einer geglätteten Axt), die mit der mesolithischen Fundserie vermischt sind. Es scheint sich dabei jedoch nur um einzelne isolierte und nicht signifikante Funde zu handeln, die vermutlich auf zufälige Verluste außerhalb des angetroffenen Siedlungskontextes zurückzuführen sind. Sie verweisen jedoch darauf, dass wir nicht von einer vollständigen Einheitlichkeit der Fundserie ausgehen dürfen. Die mesolithischen Steinartefakte sind aus Feuerstein oder aus Sandstein von mittelmäßiger Qualität gefertigt worden. Sie präsentieren eine homogene lithische Fundserie, die nur geringfügig durch einzelne Artefakte des Früh-sowie des Spätneolithikums gestört ist. Das verwendete Rohmaterial bedingte, dass sich die mesolithische Steingeräteproduktion als Abschlagsindustrie kennzeichnen lässt, bei der der Anteil der Lamellen beschränkt war. Dies bezeugt ihre geringe Nutzung als Ausgangsmaterial für die Steingeräte (Mikrolithen aus dünnen Abschlägen, bei den Gerätetypen dominieren retuschierte Abschläge und Kratzer) sowie der Abbau der Grundformen von Mikro-Kernen. Die Gruppe der Pfeilbewehrungen wird durch Spitzen mit unregelmäßiger Endretusche, dreieckigen Spitzen sowie von dicken segmentförmigen Spitzen gebildet. Alle Bewehrungen können zu den Spitzen mit unregelmäßiger Endretusche (Spitzen vom Typ Sonchamps, Spitzen vom Typ Falaise...) gerechnet werden. Trotz der geringen Größe der Fundstellen und der späteren Störungen lässt sich das Fundensemble als einheitlich charakterisieren. Es handelt sich um eine der seltenen Fundserien aus dem Endmesolithikum in der Normandie.

Resumen: Industrias líticas de tres locus del Mesolítico final en Coulmer (Orne) - Una excavación realizada en 2010 en una pequeña carretera cerca de Gacé (Orne) entregó tres locus parcialmente conservados, que se adjuntan al Mesolítico final. Las observaciones tafonómicas de estas series incluidas en el limo testimonian probablemente para los locus 1 y 2 de piezas arrastradas en profundidad por agentes naturales (madrigueras, raices...) mientras que la dispersión vertical del material del locus 3 sugiere una formación de la concentración por un fenómeno de coluvionamiento y de trampa en el débil relieve del borde de la meseta. De hecho, algunos elementos perturbadores se mezclaron con las series mesoliticas (algunos elementos modernos, dos puntas de flecha, un brazalete de esquisto, un fragmento de hacha pulida...), pero parece que sólo se refieren a elementos aislados e insignificantes y perdidos, fuera de cualquier contexto de ocupación. Sin embargo, muestran que la homogeneidad de las series no se logre plenamente. Artefactos liticos, tallados a partir de trozos de sílex o de arenisca de baja cualidad, constituyen una serie homogénea que está muy modestamente perturbada por algunos artefactos del Neolítico antiguo y final. Debido a las materias primas utilizadas, la producción mesolitica se orienta hacia un cortar en el que el componente de láminas está limitado, testigo de un uso bajo como portaherramientas y donde la producción a partir de "micro-núcleo" es frecuente. El grupo de las armaduras está representado por puntas de truncamiento gibosa, puntas triangulares y puntas segmentiformes gruesas. El conjunto parece estar relacionado con el complejo de puntas de truncamiento gibosa (Sonchamp, Falaise...). A pesar del carácter limitado de los locus y de las perturbaciones posteriores, el conjunto tiene una homogeneidad adecuada y refleja una serie demasiado rara de finales del Mesolitico en Normandía.

Schlüsselworte: locus, Spätmesolithikum, Pfeilspitzen mit unregelmässiger Endretuschee, dreieckige Spitzen, inverse Streifenretusche, kulturelle Gruppen.

Palabras clave: locus, Mesolitico final, punta de truncamiento gibosa, punta triangular, retoque inverso, grupos culturales. 